\title{
Observation of Porosity Reduction in a Densification-Prone Test Fuel Rod: Data and Analysis
}

Prepared by M. E. Cunningham, J. L. Daniel, D. D. Lanning

Pacific Northwest Laboratory

Operated by

Battelle Memorial Institute

Prepared for

U.S. Nuclear Regulatory

Commission 


\section{NOTICE}

This report was prepared as an account of work sponsored by an agency of the United States Government. Neither the United States Government nor any agency thereof, or any of their employees, makes any warranty, expressed or implied, or assumes any legal liability or responsibility for any third party's use, or the results of such use, of any information, apparatus product or process disclosed in this report, or represents that its use by such third party would not infringe privately owned rights.

Available from

GPO Sales Program

Division of Technical Information and Document Control

U. S. Nuclear Regulatory Commission

Washington, D. C. 20555

Printed copy price: $\$ 4.25$

and

National Technical Information Service

Springfield, Virginia 22161 
NUREG/CR-2042

PNL-3782

R3

\section{Observation of Porosity Reduction in a Densification-Prone Test Fuel Rod: Data and Analysis}

Manuscript Completed: September 1981

Date Published: October 1981

Prepared by

M.E. Cunningham, J.L. Daniel, D.D. Lanning

Pacific Northwest Laboratory

Richland, WA 99352

\section{Prepared for}

Division of Accident Evaluation

Office of Nuclear Regulatory Research

U.S. Nuclear Regulatory Commission

Washington, D.C. 20555

NRC FIN B2043 


\section{Availability of Reference Materials Cited in NRC Publications}

Most documents cited in NRC publications will be available from one of the following sources:

1. The NRC Public Document Room, 1717 H Street., N.W. Washingtion. DC 20555

2. The NRC/GPO Sales Program, U.S. Nuclear Regulatory Commission, Washington, DC 20555

3. The Nationa! Technical Information Service, Springfield, VA 22161

Although the listing that follows represents the majority of documents cited in NRC publications, it is not intended to be exhaustive.

Referenced docurnents available for inspection and copying for a fee from the NRC Public Document Room include NRC correspondence and internal NAC memoranda; NRC Office of Inspection and Enforcement bulletins, circulars, information notices, inspection and investigation notices; Licensee Event Reports; vendor reports and correspondence; Commission papers; and applicant and licensee documents and correspondence.

The following documents in the NUREG series are available for purchase from the NRC/GPO Sales Program: formal NRC staff and contractor reports, NRC-sponsored conference proceedings, and NRC booklets and brochures. Also available are Regulatory Guides, NRC regulations in the Code of Federal Regulations, and Nuclear Regulatory Commission issuances.

Documents available from the National Technical Information Service include NUREG series reports and technical reports prepared by other federal agencies and reports prepared by the Atornic Energy Commission, forerunner agency to the Nuclear Regulatory Commission.

Documents available from public and special technical libraries include all open literature items, such as books, journal and periodical articles, transactions, and codes and standards. Federal Register notices, federal and state legislation, and congressional feports can usually be obtained from these libraries.

Documents such as theses, dissertations, foreign reports and translations, and non-NRC conference proceedings are available for purchase from the organization sponsoring the publication cited.

Single copies of NRC draft reports are available free upon written request to the Division of Technical Information and Document Control, U.S. Nuclear Regulatory Commission, Washington, DC 20555. 


\section{ACKNOWLEDGMENTS}

The authors wish to thank the Fuel Behavior Research Branch, Office of Nuclear Regulatory Research, U.S. Nuclear Regulatory Comission (NRC) for their continued support and encouragement of the experimental program. We also thank the Halden reactor staff for the ir efforts in recording and transmitting the experimental data. Thanks are also given to $W$. D. Bennett, who aided in producing the data plots; K. R. Welsch, who conducted the image analyses; and to S. K. Edler, who edited this report. 



\section{ABSTRACT}

Instrumented fuel assembly (IFA)-431 was irradiated in the Halden Boiling Water Reactor (HBWR) for the purpose of extending the steady-state data base. Rod 6 of this assembly began irradiation with $\mathrm{UO}_{2}$ fuel of $92 \%$ theoretical density (TD) that was unstable with respect to in-reactor densification. Thermal resintering tests resulted in a final density of $95.3 \%$ TD while postirradiation examination (PIE) indicated a final density of 96.5\% TD. Observed microstructural changes were consistent with published densification studies; there was a marked depletion of submicrometer diameter pores and total pore volume. However, grain size increased only slightly, indicating that internal pellet temperatures did not reach the $1875 \mathrm{~K}$ applied in resintering tests.

Densification was observed to increase the temperatures in rod 6 , but temperatures did not become as high as for a sibling rod that simulated instantaneous densification.

Temperatures calculated with U.S. Nuclear Regulatory Comission (NRC) fuel performance computer codes were generally higher than observed temperatures. 



\section{SUMMARY}

In-reactor densification of $\mathrm{LO}_{2}$ fuel can have significant effects on the thermal and mechanica? performance of nuclear fuel rods. To provide additional data on the irradiation behavior of densifying fuel, rod 6 of instrumented fuel assembiy (IFA)-431 contained fuel of $92 \%$ theoretical density (TD) that was unstable with respect to in-reactor densification. Following an extensive preirradiation characterization, IFA-431 was irradiated from June 1975 to February 1976 and then subjected to postirradiation examination (PIE) during 1977 and 1978.

Thermal resintering tests during the precharacterization showed a density change from 92 to $95.3 \%$ TD, and PIE measurements indicated a final density of $96.5 \%$ TD after a rod average burnup of approximately $380 \mathrm{GJ} / \mathrm{kgJ}$ (4400 MWd/MTM).

Observed microstructural changes after irradiation were consistent with the measured in-reactor densification, including a marked depletion of submicrometer pores and an accompanying reduction in total pore volume proportional to pellet bumup. Grain size increased only slightly with irradiation (from an average of $6 \mu \mathrm{m}$ preirradiated to $8 \mu \mathrm{m}$ irradiated) although resintering tests at $1875 \mathrm{~K}$ on sibling pellets produced grains averaging $16 \mathrm{\mu m}$. Pronounced accumulation of porosity at the grain boundary occurred near the axis of the higher bumup pellets.

Fuel centerline temperature measurements from rod 6 have been compared to those from rod 1 (standard BWR-6) and rod 2 (large initial fuel-cladding gap to simulate instantaneous isotropic densification). Temperatures during the first power ascension showed that $\operatorname{rod} 6$ had higher temperatures than rod 1 but lower temperatures than rod 2. Rod 6 temperatures did increase as a result of densification but never became as high as those in rod 2. It was therefore concluded that the temperature effect of densification is not as severe as instantaneous isotropic densification.

Temperature data from IFA-431 has also been compared to calculations performed by the U.S. Nuclear Regulatory Cominission (NRC) fuel performance computer codes. In general, temperatures calculated by the codes, when using a 
densification mode?, were higher than observed temperatures. An uncertainty band for the calculated temperatures overlapped the observed temperatures in a number of cases. 
CONTENTS

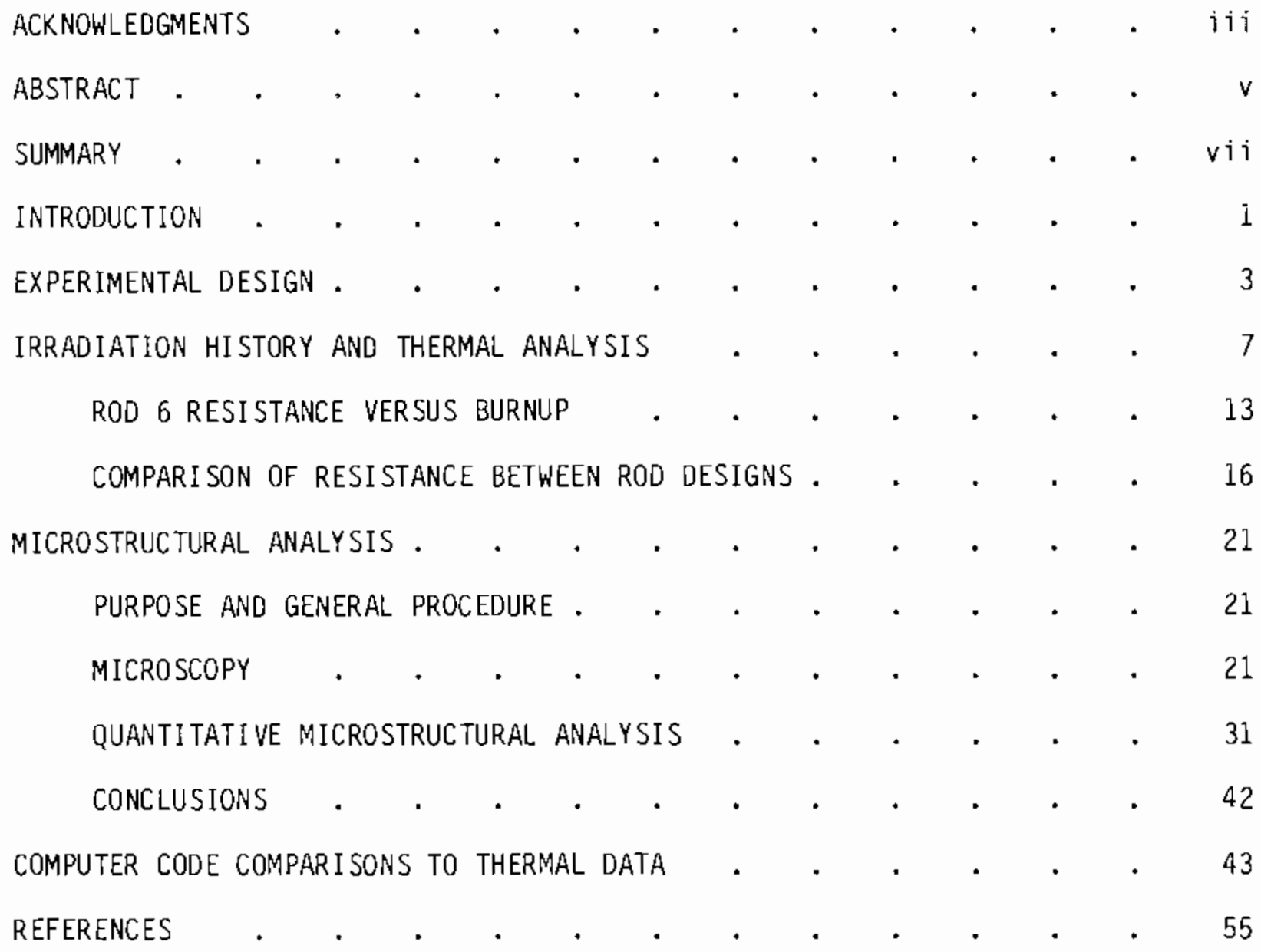

ix 


\section{FIGURES}

1 Schematic of IFA-431 . . . . . . . . . . . . . . 5

2 Overview of Irradiation Power History for IFA-431 with

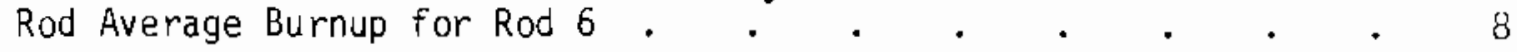

3 Upper Linear Heat Rate for Rod 6 of IFA-431 . . . . . . . y

4 Lower Linear Heat Rate for Rod 6 of IFA-431 . . . . . . 10

5 Upper Centerline Temperature for Rod 6 of IFA-431 . . . . 11

6 Lower Centerline Temperature for Rod 6 of IFA-431 • . . . 12

7 Resistance Versus Rod Average Bumup for Rod 6 of IFA-431 . . 14

8 General Resistance Behavior for Rods 6, 1 , and 3 of IFA-431 During Early Irradiation . . . . . . . . . 15

9 Comparison of Resistance for Rods 6, 1, and 2 of IFA-431 . . 17

10 Comparison of Resistance for $\operatorname{Rods} 6,1$, and 2 of IFA-432 . . 18

Centerline Temperature as a Function of Power During First
Power Ascension

12 Polished Sections of $92 \%$ TD As-Sintered Pellets Used for

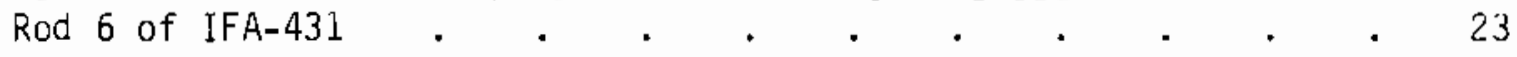

13 Polished Sections of $92 \%$ TD Irradiated Pellets

Used for Rod 6 of IFA-431 . . . . . . . . . . . . 24

14 Comparison of Polished Sections of As-Sintered and Irradiated Pellets of $92 \%$ TD Fuel . . . . . . . 25

15 Typical Radial Distribution of Porosity of $92 \%$ TD
As-Sintered Fue?
.

16 Typical Radial Distribution of Porosity of 92\% TD
As-Sintered Harwell Archive Fuel Pellet . . . . . . . . . . $\quad 27$

17 Typical Radial Distribution of Porosity of Irradiated

18 Typical Radial Distribution of Porosity of Irradiated
Pellet 13 of Rod 6 of IFA-431. $. . \quad . \quad . \quad . \quad . \quad . \quad . \quad . \quad 29$

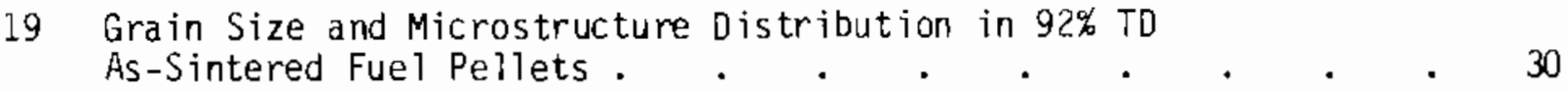


20 Grain Size and Microstructure Distribution in Irradiated Pellets from Rod 6 of IFA-431 . . . . . . . . 31

21 Pore Size and Volume Distribution in 92\% TD As-Sintered Pellets. . . . . . . . . 36

22 Pore Size and Volume Distribution in $92 \%$ TD Irradiated Pellets from Rod 6 of IFA-431. . . . . . . . 37

23 Comparison of Total Pore Volume and Pore Volume Distribution in $92 \%$ TD As-Sintered and Irradiated Pellets. . . . . 40

24 Change in Cumulative Pore Population of $92 \%$ TD Peliets During Irradiation. . . . . . . . . . . 41

25 Radial Distribution of Pore Population of $92 \%$ TD Irradiated Peliets. . . . . . . . . . 41

26 Actual Power History and Power History Used for Code Comparison . 44

27 Actual Temperature History and Temperature History Used for Code Comparison.. $. \quad . \quad . \quad . \quad . \quad . \quad . \quad .45$ 


\section{TABLES}

1 Design Parameters and Instrumentation for IFA-431 and IFA-432 . . . . . . . . . . . . . 4

2 End-of-Life Burnup for IFA-431 . . . . . . . . . 7

3 Comparison of Preirradiation Characterization of Typical 92\% TD Fuel Pellets at PNL and Harwel] . . . . . . 33

4 Effects of Irradiation on Porosity Characteristics of $92 \%$ TD Fuel Pellets from Rod 6 of IFA-431 . . . . . . 34

5 Porosity Distribution in Irradiated Pellet 39 from

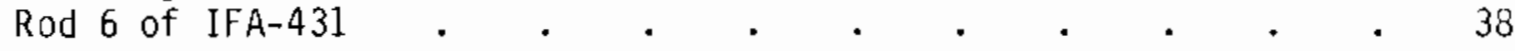

6 Porosity Distribution in Irradiated Pellet 13 from

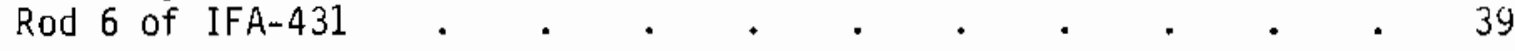

7 Grain Size of As-Sintered, Resintered, and Irradiated Pellets of $92 \%$ TO Fuel . . . . . . . . . . . 42

8 Power and Temperature History for Data/Code Comparison . . . 46

9 Common Input Parameters for Data/Code Comparison . . . . . 47

10 Computer Runs for Data/Code Comparison . . . . . . . . . 48

11 Results of Data/Code Comparison . . . . . . . . . . 49

12 Comparison of Data and Code Results . . . . . . . . . bo

13 Acceptance Bands for Data/Code Comparison . . . . . 52 


\section{INTRODUCTION}

If a loss-of-coolant accident (LOCA) should occur in a light water reactor (LWR), the short-term thermal stored energy and the long-term fission product decay heat of the fuel become the driving forces for fuel rod damage. To assess both the amount of energy that is present and its rate of removal, the U.S. Nuciear Regulatory Commission (NRC) relies on fue 1 performance computer codes that are designed to account for both fuel rod design and operating conditions. However, the individual models within a code and the net result of their interactions are continually being evaluated for accuracy and validity.

In 1972 it was discovered that the fue 7 in some commercial fuel rods had undergone considerable densification that resulted in a decreased fuel volume, increased radial and axial gaps, and some cladding deformation due to coolant pressure. The immediate concem was the effect that densification could have upon fue 1 rod behavior during LOCA conditions. The NRC quickly set forth requirements that placed restrictive limits on reactor operation. (1) Fuel vendors in tum examined their data and developed models to describe the densification behavior of $\mathrm{UO}_{2} \cdot(2,3,4)$ In addition, programs were initiated to better understand densification and to determine the characteristics of densification-resistant fue?. ${ }^{(5-9)}$

By 1974, the NRC had approved vendor models that calculated densification as a function of time or burnup. ${ }^{(10)}$ Fuel that was made up of large $\mathrm{UO}_{2}$ grains and a small fraction of small pores $(<1 \mu \mathrm{m})$ was found to be densification resistant. Calculations of fuel rod thermal behavior, now accounting for densification, were considered to be improved over pre-1972 calculations. However, in-reactor data for comparison to the code calculations was still sparse.

In 1974 the NRC began sponsoring the Experimental Support and Development of Single-Rod Fuel Codes Program at Pacific Northwest Laboratory (PNL) ${ }^{(a)}$ to provide a data base for the development and verification of NRC audit and bestestimate codes. Recognizing the need for in-reactor thermal data on densifying

(a) Operated for the U.S. Department of Energy (DOE) by Battelle Memorial Institute. 
fuel, one objective of the program was to include densifying fuel in the cesign of test irradiation rigs. The overall design of those instrumented fuel assemblies (IFAs)--IFA-431 and IFA-43\%--was predicated on the need to odtain as mucn information as possible. Thus, each of the six rods in each assembly (a) was of a different but interrelated design, which allows cross comparison of the irradiation behavior due to design differences. Rod 6 is of specific interest since it contained pellets that were not resistant to in-reactor ciensification.

IFA-431 was irradiated from June 1975 to February 1976 in the Halden Boiling Water Reactor (HBWR), Halden, Norway, and then removed; IFA-43L Degan irradiation in December 1975 and completed irradiation in unne 1981. During 1977 and 1978, destructive postirradiation examination (PIE) was performed on roc 6 of IFA-431 by AERE (b) Harweil, U.K.; and a final report on their findings was issued to PNL late in 1978. The PIE included buik and microdensity changes and metallographic examination of porosity changes. A general report discussing the irradiation of IFA-431 has been released. (1i) tecause PIE data nas been obtained only for rod 6 of IFA-431, this report wili concentrate on that rod. Some supporting in-reactor data for $\operatorname{rod} 6$ of IFA-432 wiil also be presented.

In recent years vendors have changed to densification-resistant fuels, thus reducing the need for further extensive evaluation of densifying fuel. Recognizing this change in emphasis, this report will present the observed thermal behavior of rod 6 , an analysis of fuel microstructural changes due to irradiation, and a comparison of current fuel perforiliance computer codes to the thermal data. However, this report will not present an analysis of densification kinetics.

(a) IFA-431 and IFA-432 are identically designed assemblies.

(b) Atomic Energy Research Establishment. 


\section{EXPERIMENTAL DESIGN}

In addition to studying the effects of fuel density and stability, the test parameters for IFA-431 and IFA-432 include three fuel-cladding gap sizes, two fill gas compositions, and different operating power levels. To monitor the performance of the fuel rods, each rod in each assembiy was instrumented with two fuel centerline thermocouples and a cladding axial elongation sensor. Three of the rods in each assembly were also equipped with fill gas pressure transducers. Self-powered neutron detectors (SPNDs) determine local linear heat rates in each assembly. The precharacterization report for the two assemblies ${ }^{(12)}$ contains a full description of the assemblies and a discussion of the objectives. Table 1 provides a sumnary of design characteristics, and Figure 1 is a schematic of the assemblies.

Rods 1, 2, and 6 are of particular concem in this anaiysis. The basic design features of these rods are:

- Rod 1 serves as the standard or reference rod for this program. It simulates a typical BWR-6 fuel rod and was fabricated with stable fuel of $95 \%$ theoretical density (TD), a fuel-cladding gap of $230 \mu \mathrm{m}$, and helium fill gas. The active fuel length was $0.57 \mathrm{~m}$ for all rods.

- Rod 2 simulates a fuel rod with unstabie fuel of $92 \%$ TD that instantaneously densified to $96.5 \%$ TD. The fabricated rod had a fuelcladding gap of $380 \mu \mathrm{m}, 95 \%$ TO stable fuel, and helium fill gas.

- Rod 6 is a fuel rod with densifying fuel that was initially 92\% TD but was unstable with respect to in-reactor densification. The initial fuel-cladding gap was $230 \mu \mathrm{m}$, and the fill gas was helium. 
TABLE 1. Design Parameters and Instrumentation for IFA-431 and IFA-432

IFA-431 Peak Power - $33 \mathrm{~kW} / \mathrm{m}$

\begin{tabular}{|c|c|c|c|c|c|c|c|c|c|}
\hline \multirow[b]{2}{*}{$\begin{array}{l}\text { Rod } \\
\text { No. }\end{array}$} & \multirow[b]{2}{*}{$\begin{array}{c}\text { Pellet } \\
\text { Diameter, mm }\end{array}$} & \multirow{2}{*}{$\begin{array}{l}\text { Cold } \\
\text { Dianetral } \\
\text { Gap, (a) }\end{array}$} & \multirow[b]{2}{*}{$\begin{array}{l}\text { Fill } \\
\text { Gas } \\
\end{array}$} & \multirow{2}{*}{$\begin{array}{c}\text { Fue l } \\
\text { Oensity, } \\
\% \text { To }\end{array}$} & \multirow[b]{2}{*}{$\begin{array}{c}\text { Fuel } \\
\text { Type (b) }\end{array}$} & \multicolumn{4}{|c|}{ Instrumentation } \\
\hline & & & & & & $\begin{array}{l}\text { Tempe } \\
\text { Upper }\end{array}$ & $\frac{\text { ature }}{\text { Lower }}$ & Pressure & $\begin{array}{l}\text { wasiong } \\
\text { Lengtn }\end{array}$ \\
\hline 1 & 10.681 & 230 & $\mathrm{He}$ & 45 & Stable & $T C^{(C)}$ & $\overline{T C}$ & $P T^{i d j}$ & Es (e) \\
\hline 2 & 10.528 & 380 & $\mathrm{He}$ & 95 & Stable & TC & TC & -- & $E S$ \\
\hline 3 & 10.858 & 50 & He & 95 & Stable & IC & TC & -- & $E S$ \\
\hline 4 & 10.681 & 230 & $\mathrm{xe}$ & 95 & Stab le & $T C$ & $T C$ & -- & eS \\
\hline 5 & 10.681 & 230 & $\mathrm{He}$ & 92 & Stable & TC & TC & PT & ES \\
\hline 6 & 10.681 & 230 & He & 92 & Unstable & TC & $T C$ & PT & ES \\
\hline
\end{tabular}

IFA-432 Peak Power - $49 \mathrm{kw} / \mathrm{m}$

$\begin{array}{lr}10.681 & 230 \\ 10.528 & 380 \\ 10.833 & 70 \\ 10.681 & 230 \\ 10.681 & 230 \\ 10.681 & 230 \\ 10.528 & 380 \\ 10.681 & 230 \\ 10.732 & 180\end{array}$

$\begin{array}{ll}\text { He } & 95 \\ \text { He } & 95 \\ \text { He } & 95 \\ \text { Xe } & 95 \\ \text { He } & 92 \\ \text { He } & 92 \\ \text { He } & 95 \\ \text { He } & 95 \\ \text { He } & 95\end{array}$

$\begin{array}{lll}\text { Stable } & T C & T C \\ \text { Stable } & \text { LT }(f) & T C \\ \text { Stable } & T C & T C \\ \text { Stable } & T C & T C \\ \text { Stable } & T C & T C \\ \text { Unstable } & \text { TC } & \text { TC } \\ \text { Stable } & -- & -- \\ \text { Stable } & -- & -- \\ \text { Stable } & -- & --\end{array}$

PT

1
2
3
4
5
6
7
8
9

(a) Cladding for all rods had an outside diameter (00) of $12.789 \mathrm{~mm}$ and an inside diameter (10) of $10.909 \mathrm{~mm}$; diametral gap = cladding ID minus peliet diameter.

(b) With respect to in-reactor densification.

(c) $\mathrm{TC}=$ thermocouple.

(d) $P T=$ pressure transducer.

(e) $E S$ = elongation sensor.

(f) $U T=$ ultrasonic thermometer. 


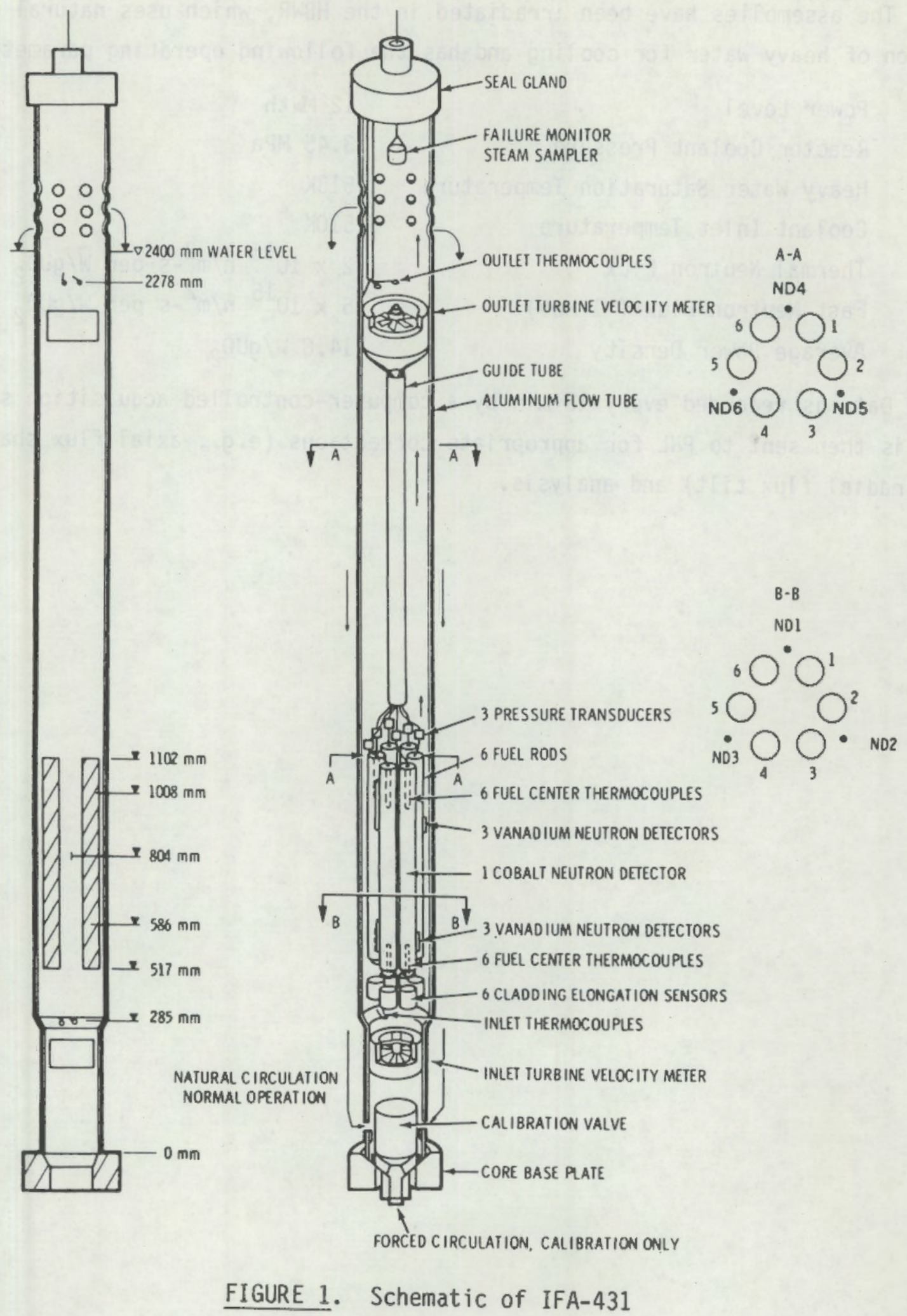


The assemblies have been irradiated in the HBWR, which uses natural circulation of heavy water for cooling and has the following operating parameters:

Power Leve 1

Reactor Coolant Pressure

Heavy Water Saturation Temperature

Coolant Inlet Temperature

Thermal Neutron Flux

Fast Neutron Flux (>1 MeV)

Average Power Density
12 MNth

$3.45 \mathrm{MPa}$

$513 \mathrm{~K}$

$510 \mathrm{~K}$

$2 \times 10^{16} \mathrm{n} / \mathrm{m}^{2}-\mathrm{s}$ per $\mathrm{W} / \mathrm{guO}_{2}$

$5 \times 10^{15} \mathrm{n} / \mathrm{m}^{2}-\mathrm{s}$ per $\mathrm{W} / \mathrm{gUO}_{2}$

$14.8 \mathrm{~W} / \mathrm{gUO}_{2}$

Data is recorded every 15 min by a computer-controlled acquisition system and is then sent to PNL for appropriate corrections (e.g., axial flux shape and radial flux tilt) and analysis. 


\section{IRRADIATION HISTORY AND THERMAL ANALYSIS}

The irradiation of IFA-431 began June 8, 1975, and ended February 13, 1976. When the assembly was removed from the reactor, the average burnup was approximately $380 \mathrm{GJ} / \mathrm{kgU}$ (4400 MWd/MTM); Table 2 lists the local end-of-life (EOL) burnups for the six rods in IFA-431. After cooling for 123 days, IFA-431 was shipped to the Kjeller Hot Lab, Kjeller, Norway, for nondestructive examination (NDE) of all rods. Rod 6 was then sent to AERE Harwe11, U.K., for destructive PIE to determine fission gas release, microstructural changes, density changes, and burnup analysis; this work was completed in August 1978.

\section{TABLE 2. End-of-L ife Burnup for IFA-431}

\begin{tabular}{|c|c|c|c|c|c|c|}
\hline Thermocouple & & & 1 Burn & $\mathrm{GJ} / \mathrm{kg}$ & & \\
\hline Position & Rod 1 & Rod 2 & Rod 3 & Rod 4 & Rod 5 & Rod 6 \\
\hline Lower & 314 & 324 & 336 & 325 & 315 & 308 \\
\hline Upper & 432 & 447 & 463 & 449 & 434 & 425 \\
\hline Rod Average & 373 & 386 & 400 & 387 & 375 & 367 \\
\hline
\end{tabular}

(a) $\mathrm{MWd} / \mathrm{MTM}=\mathrm{GJ} / \mathrm{kgU} \times 11.574$.

The irradiation history of IFA-431 is summarized in Figure 2 where reactor power and assembly average burnup are plotted as a function of real time. Linear heat rates at the upper and lower thermocouples of rod 6 are presented in Figures 3 and 4 as a function of loca 1 burnup, and corresponding centerline temperatures are shown in Figures 5 and 6 .

Thermal resistance has been found to be a useful aid in the analysis of fuel rod thermal behavior. As the heat transfer behavior of a fuel rod changes (e.g., due to densification, fuel cracking, and/or fission gas release), the thermal resistance changes. Specifically, thermal resistance is the ratio of the difference between the fuel centerline temperature and the coolant temperature to the local linear heat rate:

$$
R_{T}=\frac{T_{C L}-T_{W}}{L H R \times 1000}
$$




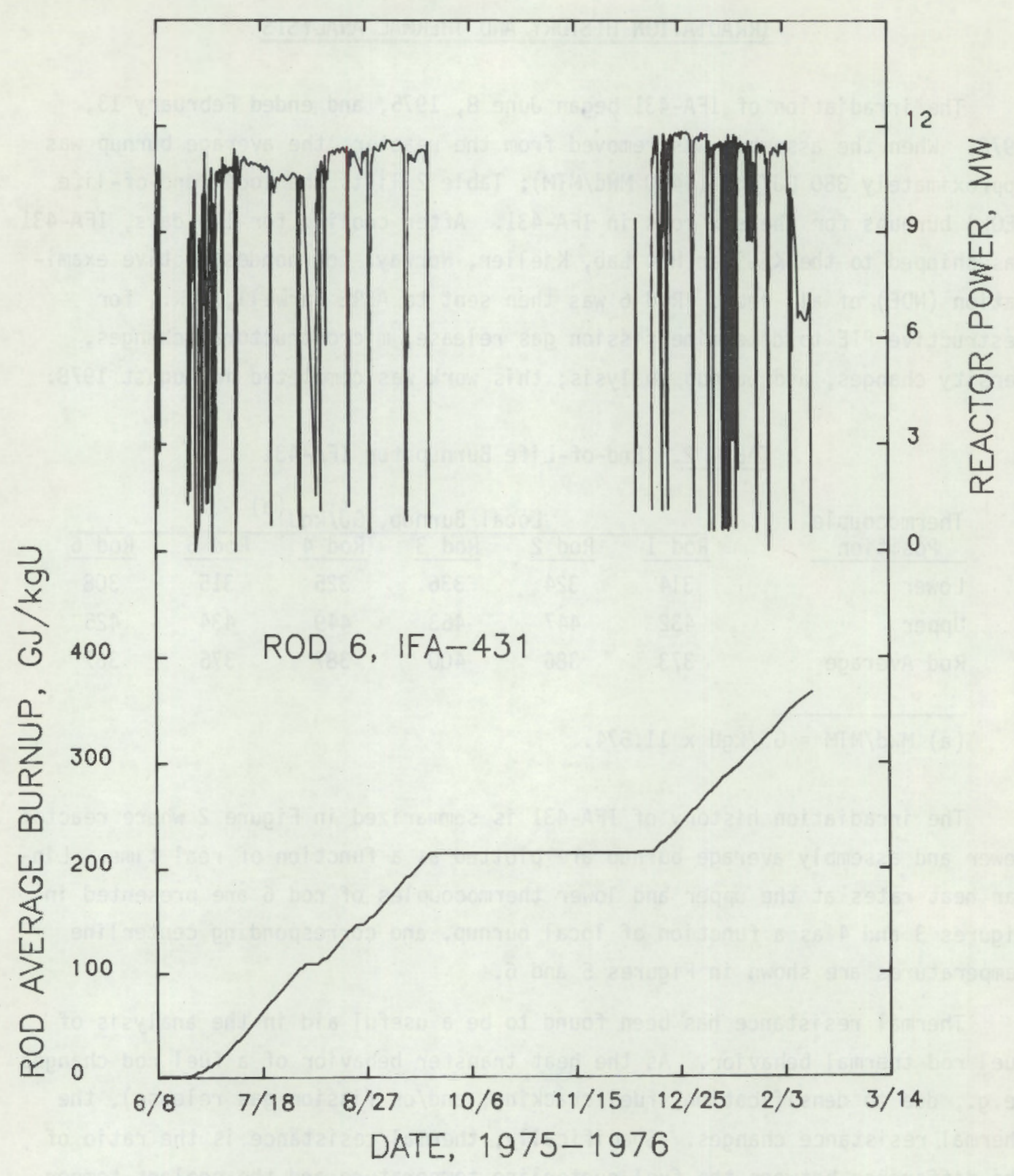

FIGURE 2. Overview of Irradiation Power History for IFA-431 with Rod Average Burnup for Rod 6 


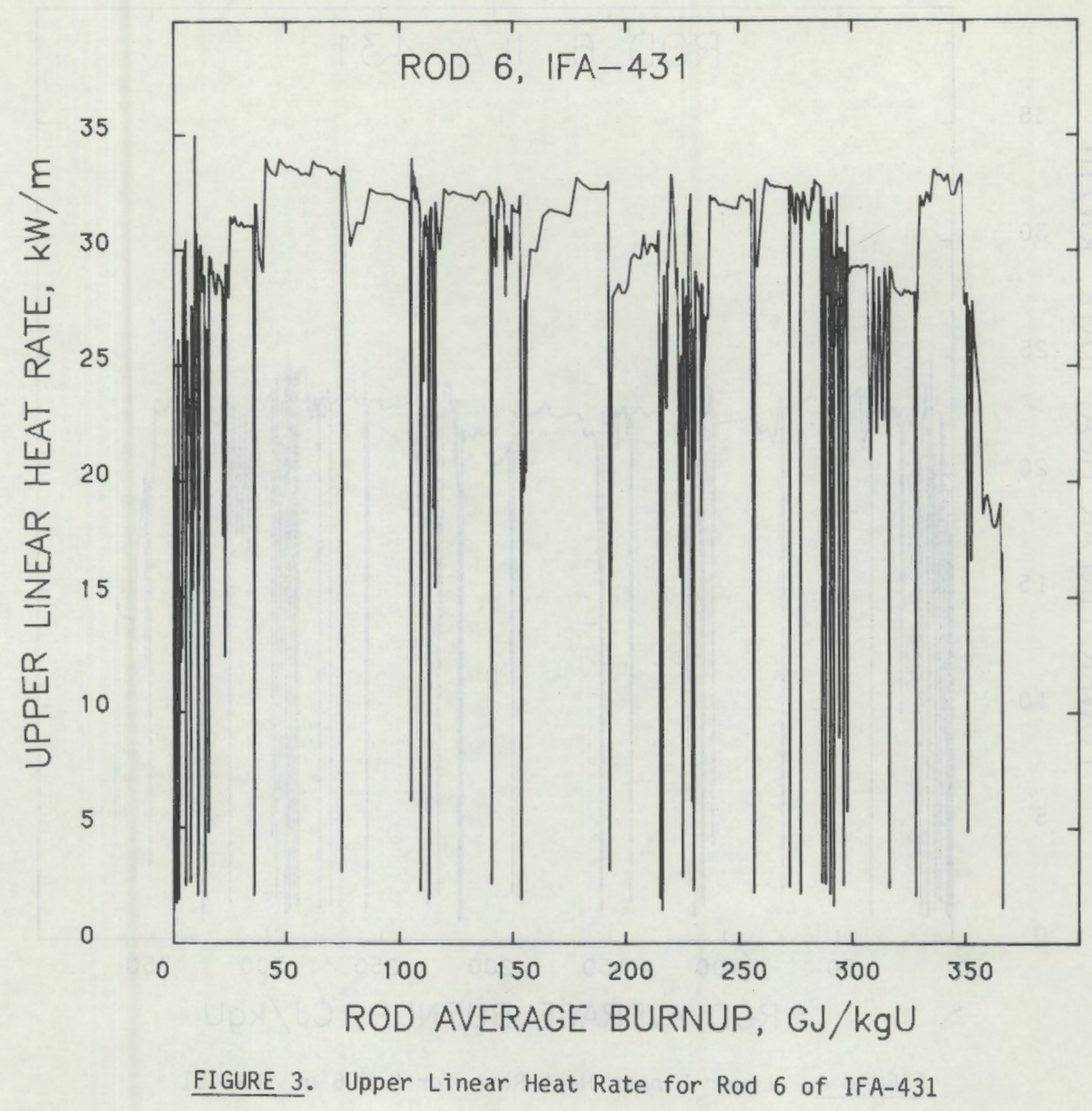




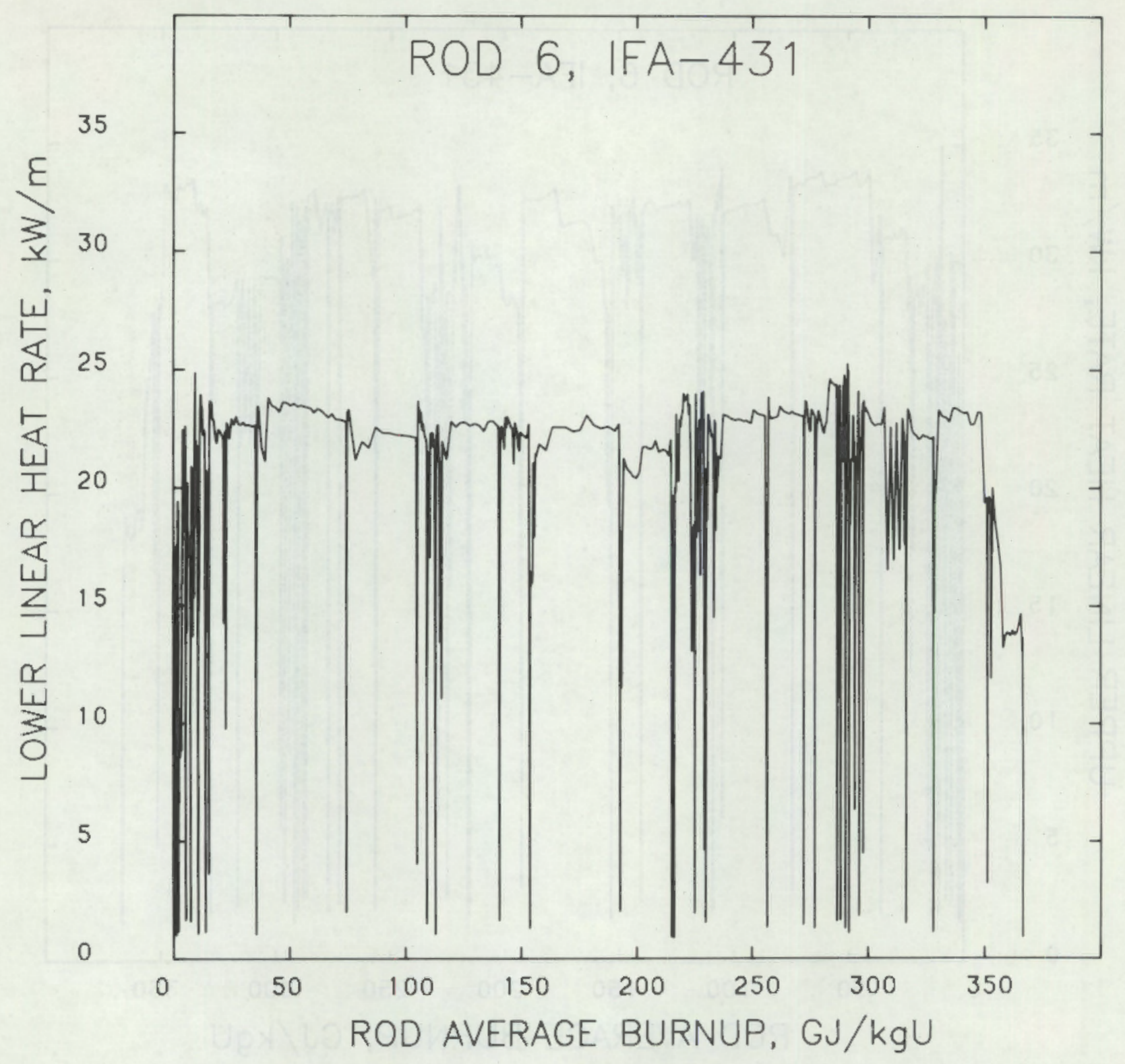

FIGURE 4. Lower Linear Heat Rate for Rod 6 of IFA-431 


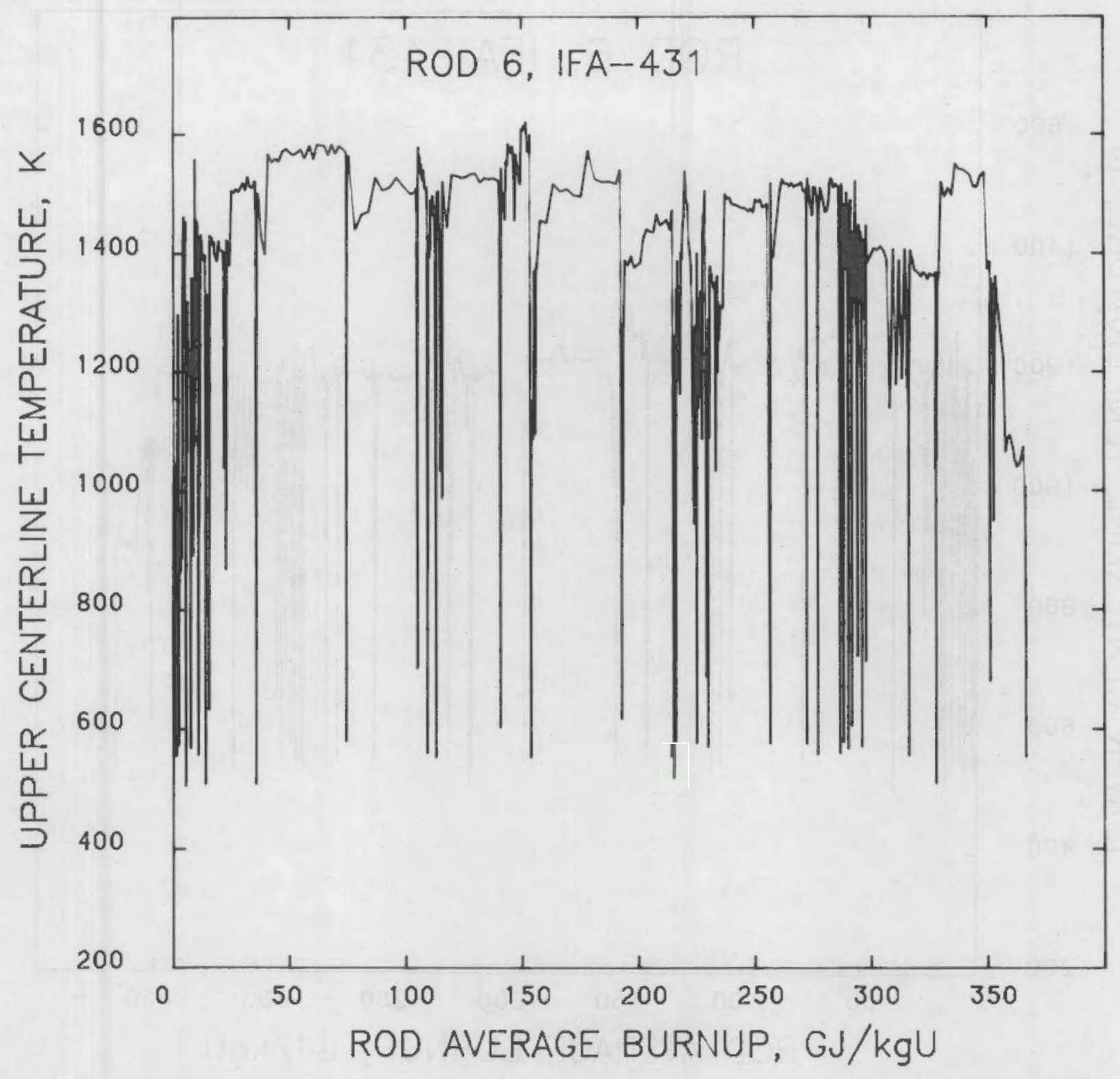

FIGURE 5. Upper Centerline Temperature for Rod 6 of IFA-431 


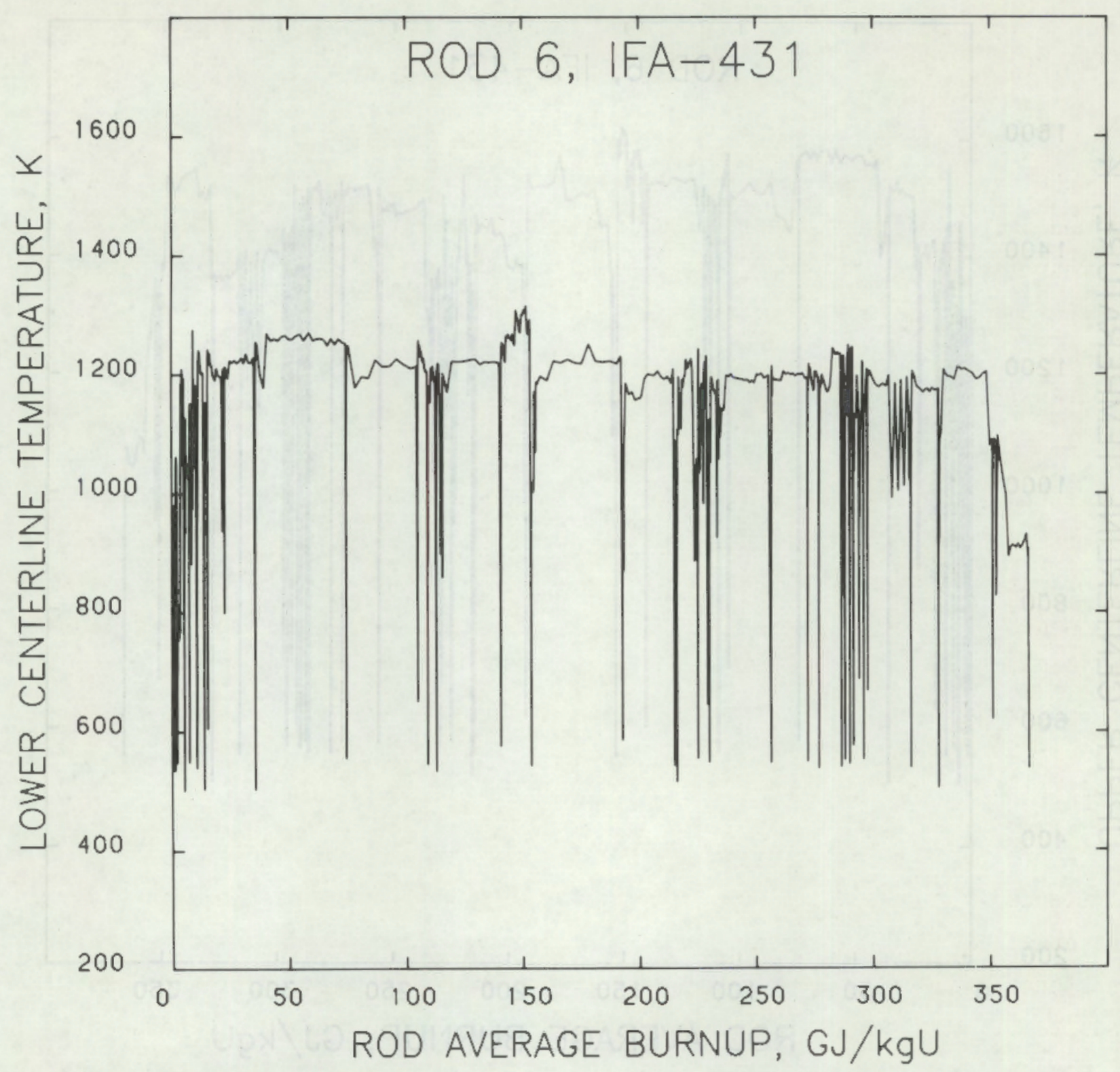

FIGURE 6. Lower Centerline Temperature for Rod 6 of IFA-431 
where $R_{T}=$ total thermal resistance, $m-K / W$

$T_{C L}=$ fuel center line temperature, $K$

$\mathrm{T}_{\mathrm{W}}=$ coolant temperature, $\mathrm{K}$

LHR = local linear heat rate, $\mathrm{kW} / \mathrm{m}$.

Defined in this manner, thermal resistance is sensitive to changes in the thermal response of a fuel rod. A more extensive discussion of thermal resistance can be found in Reference 13.

\section{ROD 6 RESISTANCE VERSUS BURNUP}

Figure 7 presents the thermal resistance of rod 6 at the upper and lower thermocouple positions as a function of rod average burnup. Three principal regions are of interest in this figure. First, the resistance increased approximately $19 \%$ (from 0.026 to $0.031 \mathrm{~m}-\mathrm{K} / \mathrm{W}$ ) during the first $4 \mathrm{GJ} / \mathrm{kgU}$ and was followed by another $6 \%$ increase (from 0.031 to $0.033 \mathrm{~m}-\mathrm{K} / \mathrm{W}$ ) during the following $39 \mathrm{GJ} / \mathrm{kgU}$. Second, the resistance after the 3 -month shutdown $(215 \mathrm{GJ} / \mathrm{kgU}$ ) was approximately $5 \%$ lower than it was before the shutdown. Third, an approximately step increase in resistance from 141 to $153 \mathrm{GJ} / \mathrm{kgU}$ was followed by a return to preceding values.

A preliminary analysis might attribute the beginning-of-life (BOL) resistance increase entirely to densification; however, a closer examination indicates that densification may not have occurred immediately. The general resistance behavior of rods 6, 1 (standard rod), and 3 (small-gap, high-gap conductance) over the first 14 days at power (shutdown time is not included) is compared in Figure 8 . (a) The behavior is the same for all three rods for approximately the first 8 days. Since the fuel in rods 1 and 3 was expected to have minimal densification, this initial resistance change is attributed to fuel cracking and related effects. Additionally, fuel centerline temperatures for rod 6 during this period ranged from 1025 to $1675 \mathrm{~K}\left(750\right.$ to $\left.1400^{\circ} \mathrm{C}\right)$, with the peak temperatures occurring for only approximately $36 \mathrm{~h}$. Since the fuel

(a) The initial resistance differences among the three rods are due to design differences: Rod 3 has the smallest gap and thus the lowest resistance; although rods 1 and 6 have the same gap, the fuel in rod 6 has a higher porosity and therefore lower thermal conductivity. (12) 


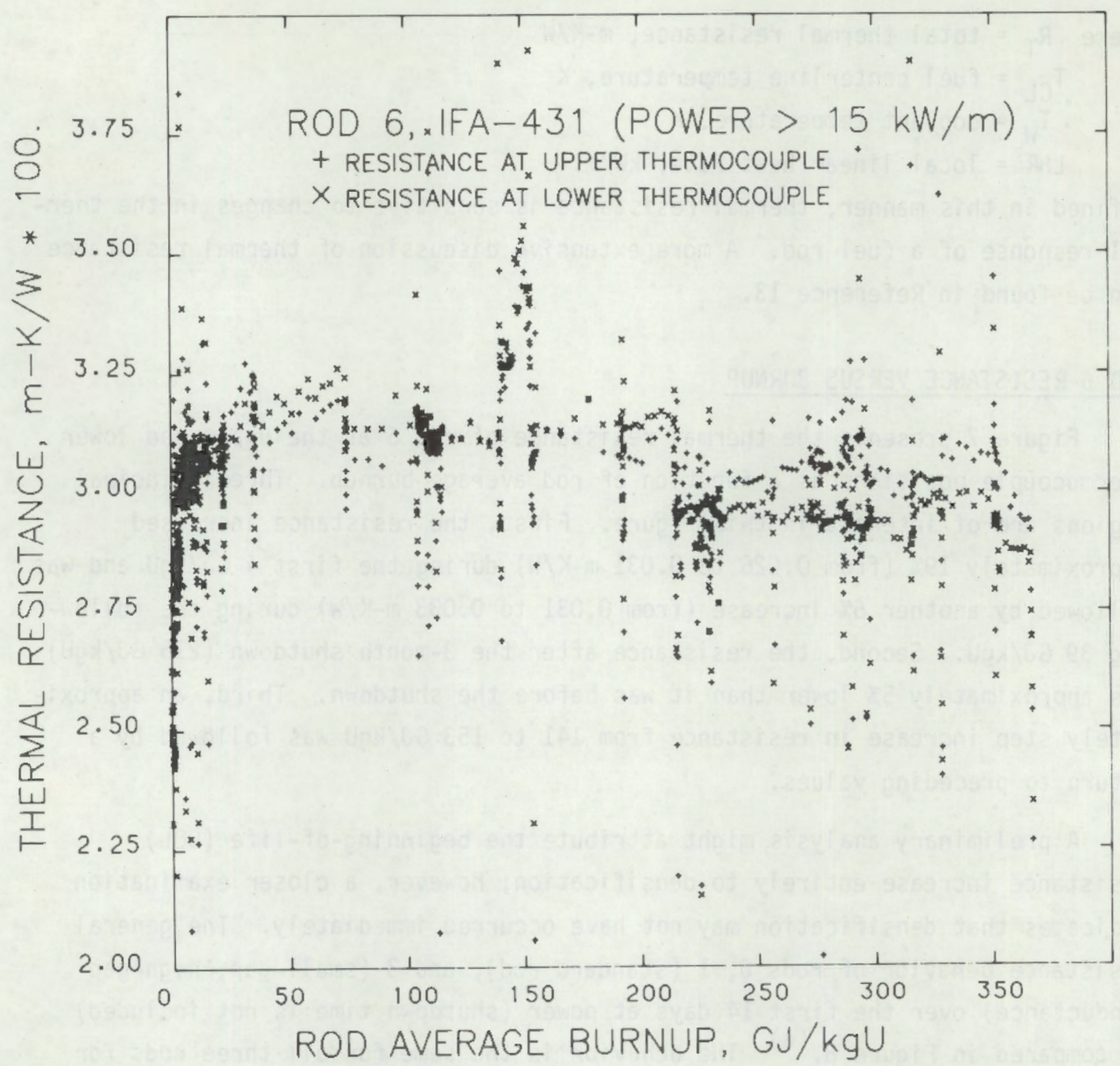

FIGURE 7. Resistance Versus Rod Average Burnup for Rod 6 of IFA-431

was initially sintered at $1973 \mathrm{~K}$ for $8 \mathrm{~h}$, this lower temperature may have been insufficient for additional sintering and densification.

After 8 days at power, the resistance of rod 6 began increasing while the resistance of rods 1 and 3 remained constant. Measured centerline temperatures during this period were greater than $1700 \mathrm{~K}$ for 3.5 days and greater than $1800 \mathrm{~K}$ for the last 2.5 days (see Figure 8 ). This resistance increase is attributed to densification of the fuel in rod 6 . 


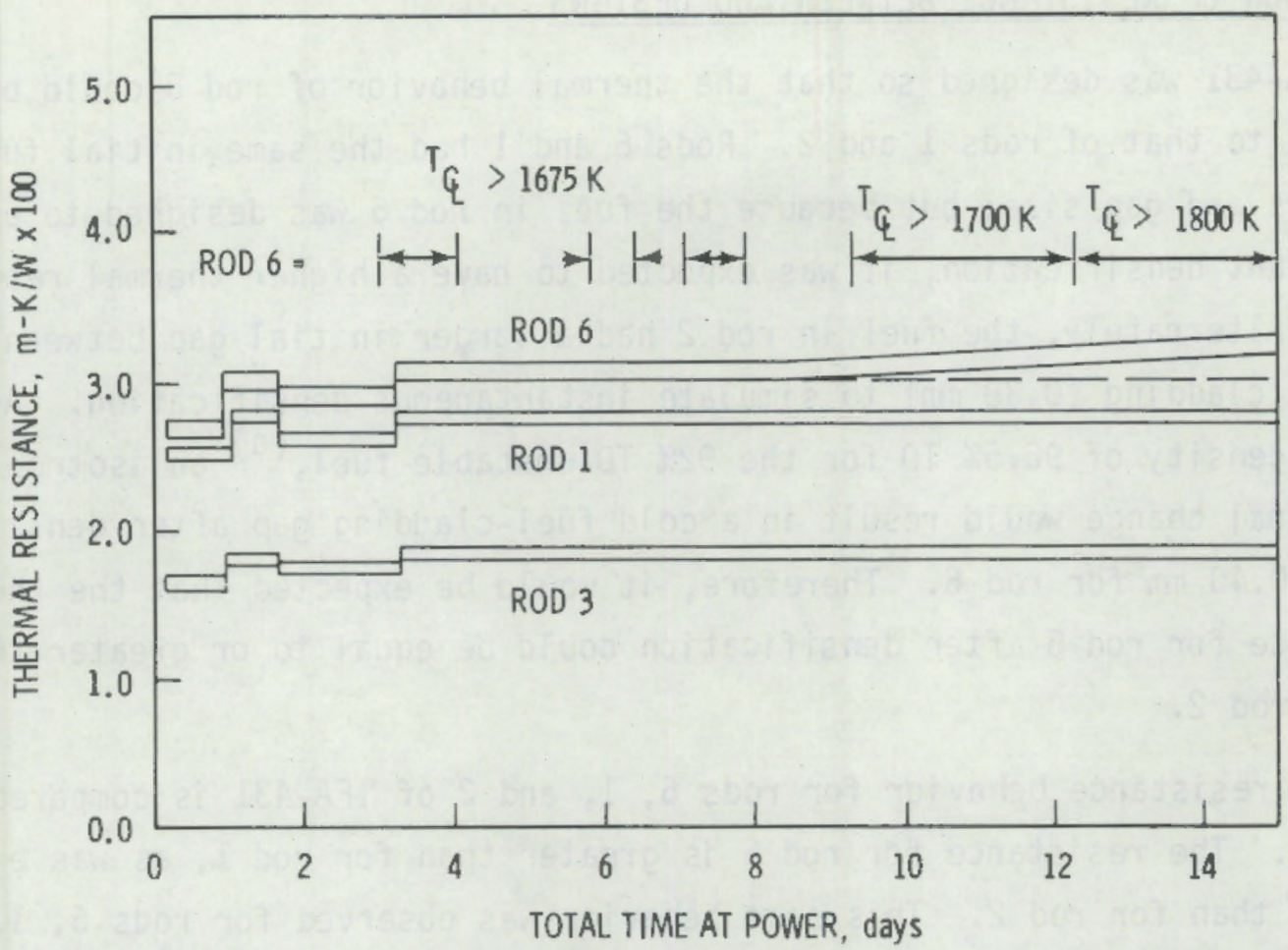

FIGURE 8. General Resistance Behavior for Rods 6,1 , and 3 of IFA-431 During Early Irradiation

The $5 \%$ drop in resistance after the extended shutdown (Figure 7 ) was also observed in the other rods of IFA-431 and is believed to be due to settling of the fuel pellet fragments, which then resulted in a reduction of the effective fuel-cladding gap and the thermal resistance. The rise in resistance seen during the burnup span from 141 to $153 \mathrm{GJ} / \mathrm{kgU}$ is believed to be an instrumentation error. No physical reasons for such a resistance spike are suspected, and the other rods in IFA-431 showed similar resistance spikes during the same time period along with indications of anomalous instrumentation behavior.

The observed increase in thermal resistance for rod 6 should be principally attributed to densification and not fission gas release. Pressure measurements during the irradiation indicated low fission gas release, and PIE measurements confirmed this. The final gas mixture for rod 6 was approximately 85\% helium, $10 \%$ nitrogen and carbon monoxide, and $5 \%$ fission gas. 
IFA-431 was designed so that the thermal behavior of rod 6 could be compared to that of rods 1 and 2. Rods 6 and 1 had the same initial fuel diameters and gap size; but because the fuel in rod 6 was designed to undergo significant densification, it was expected to have a higher thermal resistance. Alternately, the fuel in rod 2 had a larger initial gap between the fuel and cladding $(0.38 \mathrm{~mm})$ to simulate instantaneous densification. Assuming a final density of $96.5 \%$ TD for the $92 \%$ TD unstable fue $1,{ }^{(a)}$ an isotropic dimensional change would result in a cold fuel-cladding gap after densification of $0.40 \mathrm{~mm}$ for rod 6 . Therefore, it would be expected that the therma 1 resistance for rod 6 after densification could be equal to or greater than that of rod 2.

The resistance behavior for rods 6,1 , and 2 of IFA-431 is compared in Figure 9. The resistance for rod 6 is greater than for rod 1, as was expected, but less than for rod 2. This same behavior was observed for rods 6,1 , and 2 of IFA-432 as is shown in Figure 10. One point of concem involves the initial resistance data. As stated earlier, densification does require time and temperature and the initial resistance differences observed in Figures 9 and 10 are basically due to design differences. This is further illustrated in Figure 11, where centerline temperature as a function of power is plotted for the first rise to power. Rod 2 has the largest fuel-cladding gap and the highest centerline temperature. Rods 6 and 1 have the same gap; the lower density in rod 6 is principally responsible for its higher temperature.

By comparing the resistance behavior of rods 6,1 , and 2 and recalling that the observed total thermal resistance is dependent on densification, fuel cracking and relocation, and other factors, it can be concluded that densification does increase fuel temperatures. However, the observed temperature increase due to densification ( $\operatorname{rod} 6$ ) was less than if instantaneous densification and isotropic shrinking had occurred.

(a) Final density for rod 6 of IFA-431 fuel was measured at $96 \pm 1 \%$ TO. (11) 


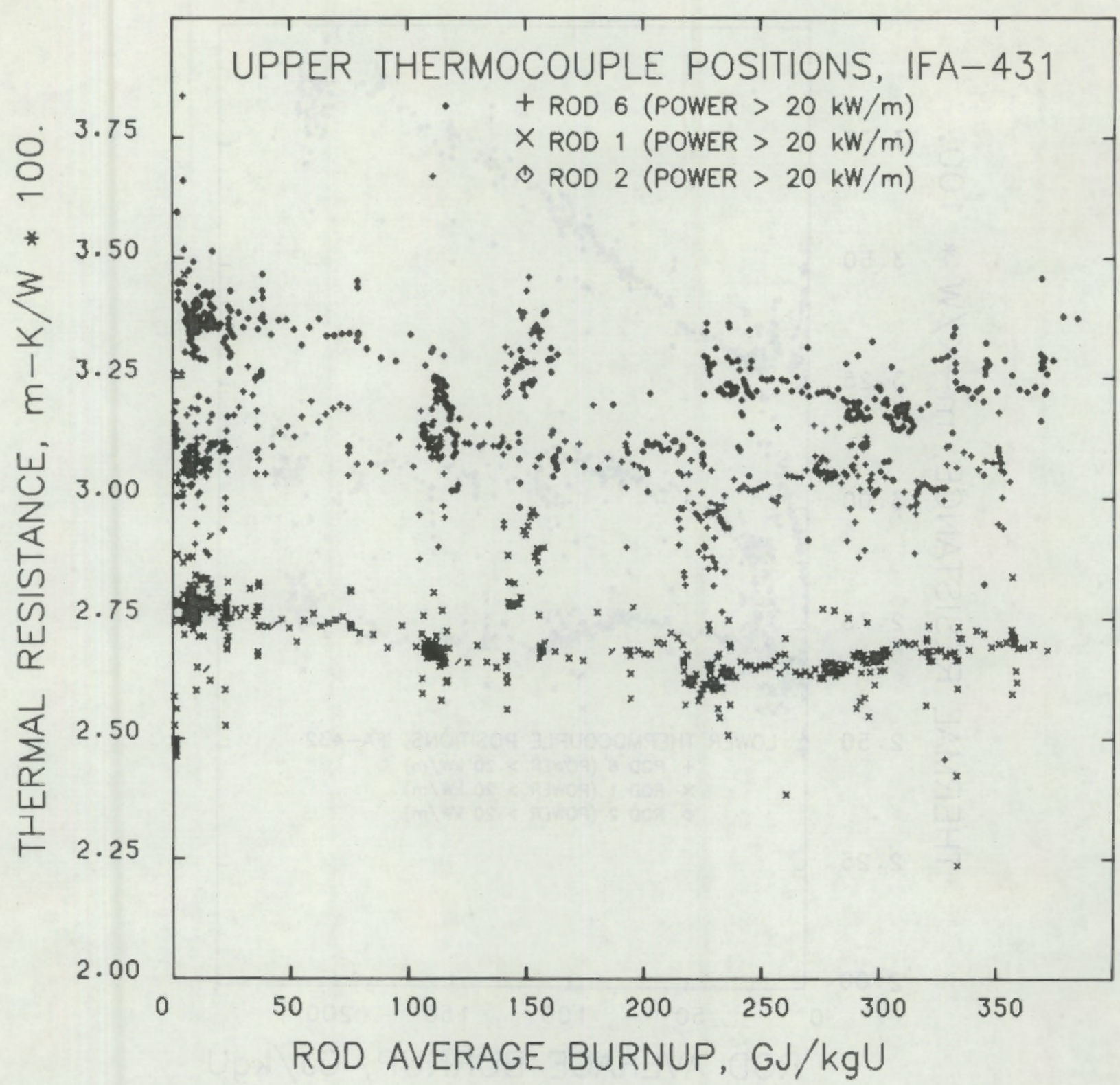

FIGURE 9. Comparison of Resistance for Rods 6,1 , and 2 of IFA-431 


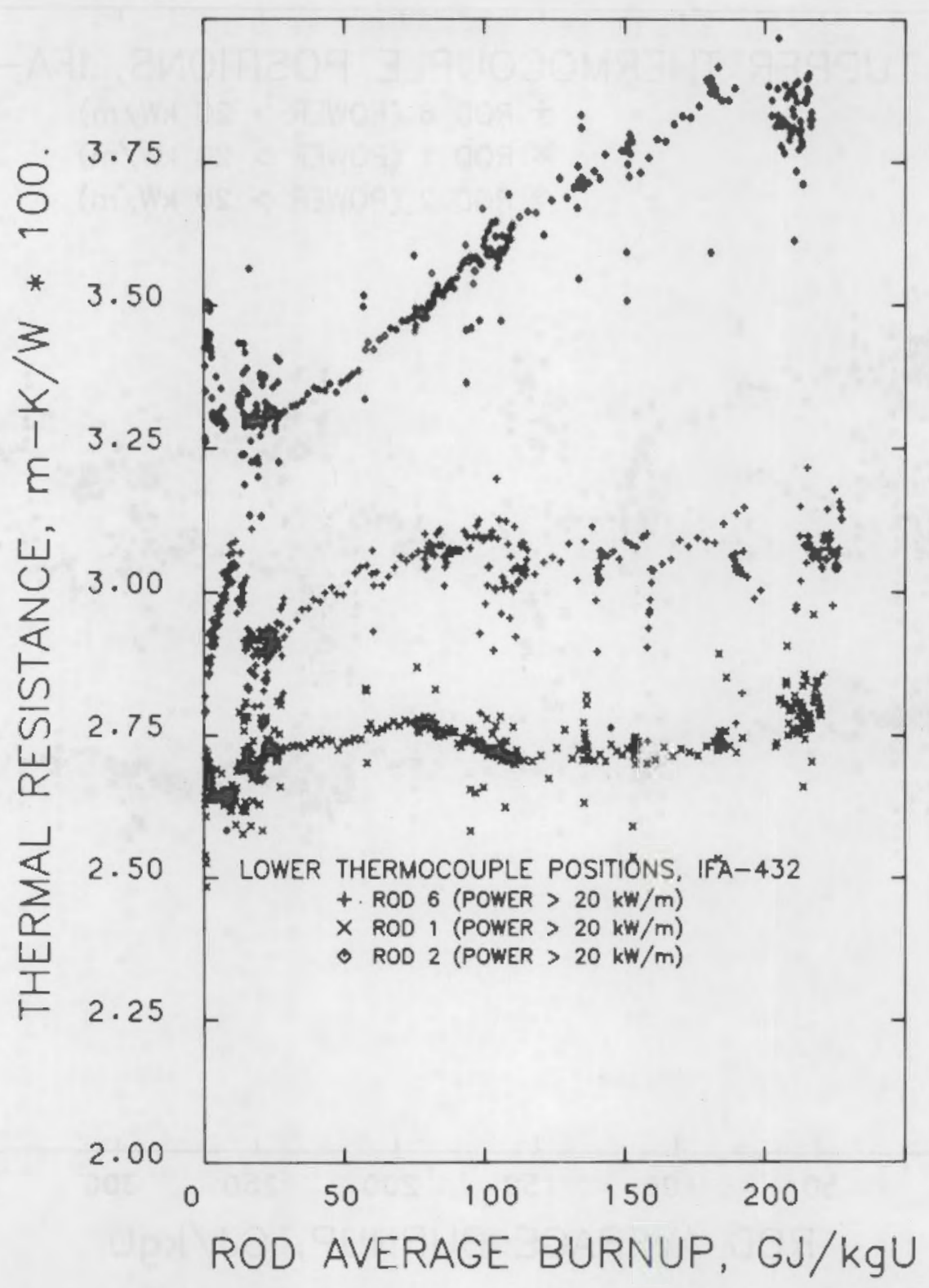

FIGURE 10. Comparison of Resistance for Rods 6,1 , and 2 of IFA-432 


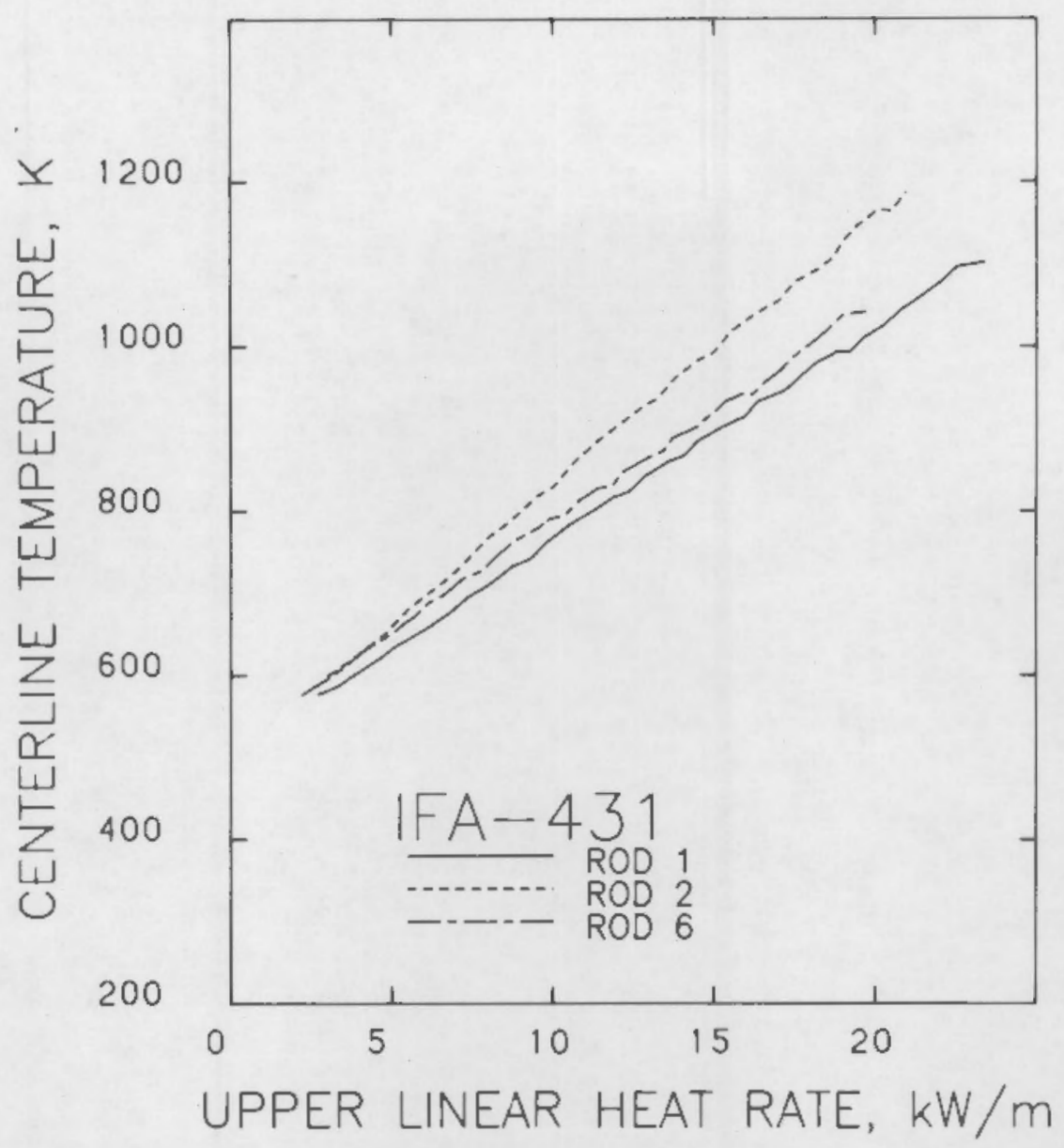

FIGURE 11. Centerline Temperature as a Function of Power During First Power Ascension 



\section{MICROSTRUCTURAL ANALYSIS}

\section{PURPOSE AND GENERAL PROCEDURE}

Microstructural analysis of pellets 13 and 39 of rod 6 of IFA-431 was conducted to compare the pre- and postirradiated structures and evaluate the effects of irradiation on unstable fuel. Of particular interest were the changes in porosity and grain size, which are especially significant relative to densification behavior.

The analysis was conducted as a cooperative effort by PNL and Harwe11. At PNL, detailed precharacterization of sibling pellets of this fuel type was conducted as reported in Reference 12. That work included high-resolution metallography, optical and scanning electron microscopy, quantitative image analysis of porosity, and estimation of grain size. From this data the characteristics of inherent porosity and the propensity for densification were determined. At Harwe 11, metallography and microscopy were conducted on an as-sintered sibling archive pellet to demonstrate that Harwell specimen preparation, metallography, and microscopy procedures to be applied to the irradiated pellets were comparable. The Harwell micrographs were quantitatively analyzed at PNL using the same procedures as for the PNL preirradiation characterization work. The procedures generally followed the methods outlined in Reference 12.

In this report, the qualitative results of metallography and representative illustrations of microstructure obtained both in precharacterization and PIE work are presented and provide a visual comparison of the fuel materials. Quantitative data from image analysis of those microstructures is presented, and the pre- and postirradiation comparisons are summarized.

\section{MICROSCOPY}

Microscopy was conducted on polished sections of pellets prepared by standard metallography techniques. PNL precharacterization work was conducted on two randomly selected pellets of this unstable fuel type that were sectioned transversely and longitudinally for microscopy. At Harwe11, metallography on 
archive and irradiated pellets was conducted on transverse sections only. Figure 12 shows the polished sections of as-sintered pellets at low magnification; the locations of the subsequent high-magnification photomicrography are indicated. Similarly, the cross sections of the irradiated pellets examined are shown in Figure 13. The sites for subsequent detailed porosity studies include a representative sampling of peripheral, midradius, and center locations. This procedure permits identification of any differences in densification or pore size distribution relative to radial locations in each pellet and allows verification that the as-sintered pellets were homogeneous. Observed qualitative differences between as-sintered and irradiated fuel are illustrated in Figure 14. There are significantly fewer pores present after irradiation, which is typical of densification.

Examples of more detailed preirradiation microscopy conducted at PNL and Harwell are compared in Figures 15 and 16 . Both of these figures show a significant number of small pores (visible at the higher magnification) as well as a un iform distribution of larger pores. Some difficulties were initially experienced at the Harwell laboratory with pull-out from the pellet surface during polishing; and although these problems were largely overcome by a modified polishing method, the equipment that was utilized was unable to provide as sharp a definition of pores at the higher magnification as in the PNL series. However, qualitatively, the two sets of micrographs are comparable.

The microscopy conducted on the two irradiated pellets is illustrated in Figures 17 and 18. As mentioned previously, irradiation tended to densify the pellets, resulting in fewer pores. The lower burnup pellet (39) shows the initial stage of a grain boundary concentration of pores; the higher burnup pellet (13) contains a pronounced concentration of pores in the grain boundaries (in the axial regions in particular where the temperature was the highest). Grain definition is also enhanced in both of these irradiated pellets and particularly in pellet 13.

Grain size measurements were conducted on etched surfaces of the same preand postirradiation pellets. Figure 19 shows the preirradiation condition observed at PNL and Harwe11. In the PNL precharacterization, the grains are 

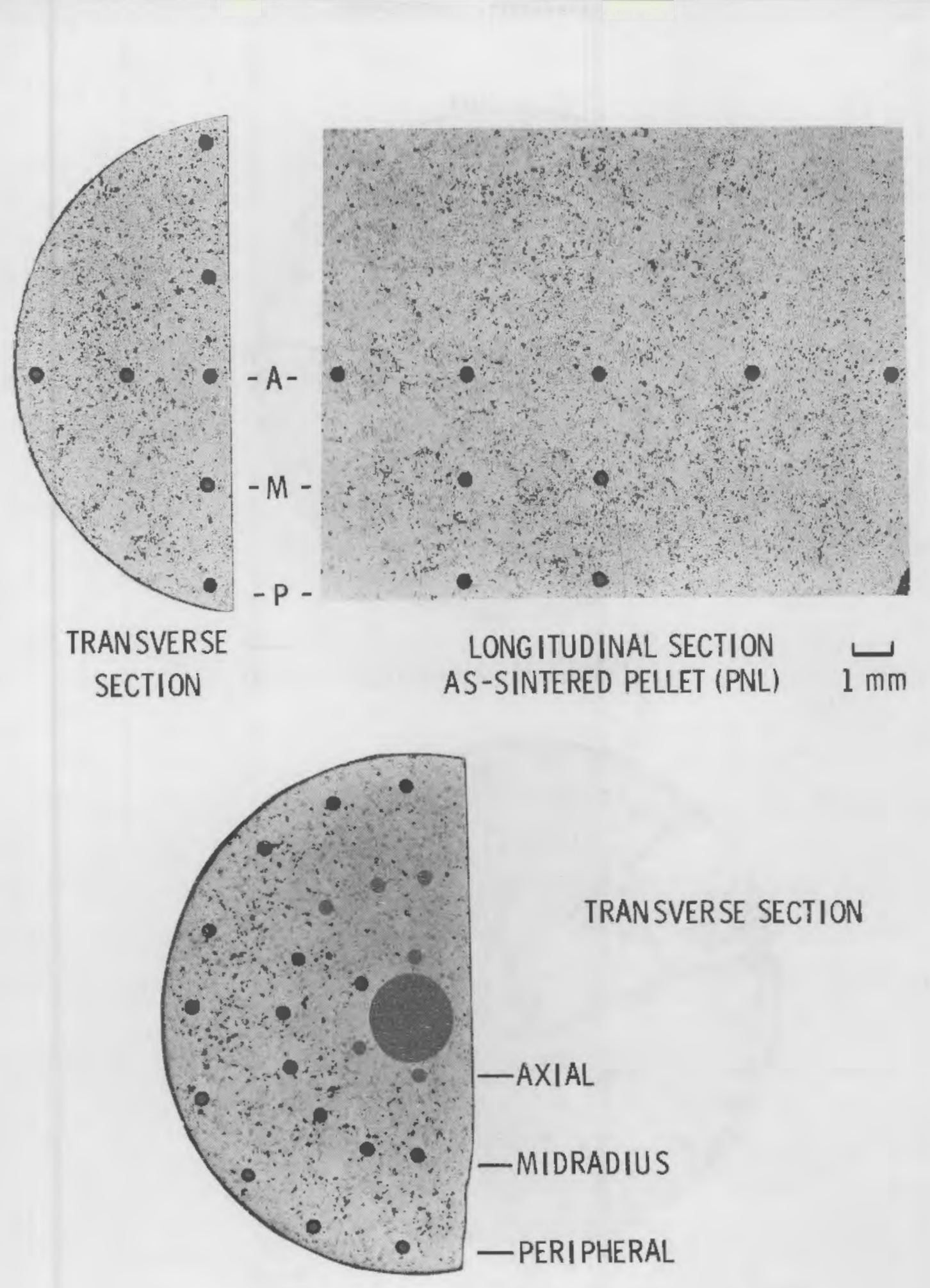

\section{AS-SINTERED ARCHIVE PELLET (HARWELL) $1 \mathrm{~mm}$}

FIGURE 12. Polished Sections of $92 \%$ TD As-Sintered Pellets Used for Rod 6 of IFA-431. Locations of photomicrography for study of porosity, microstructure, and grain size are shown. 

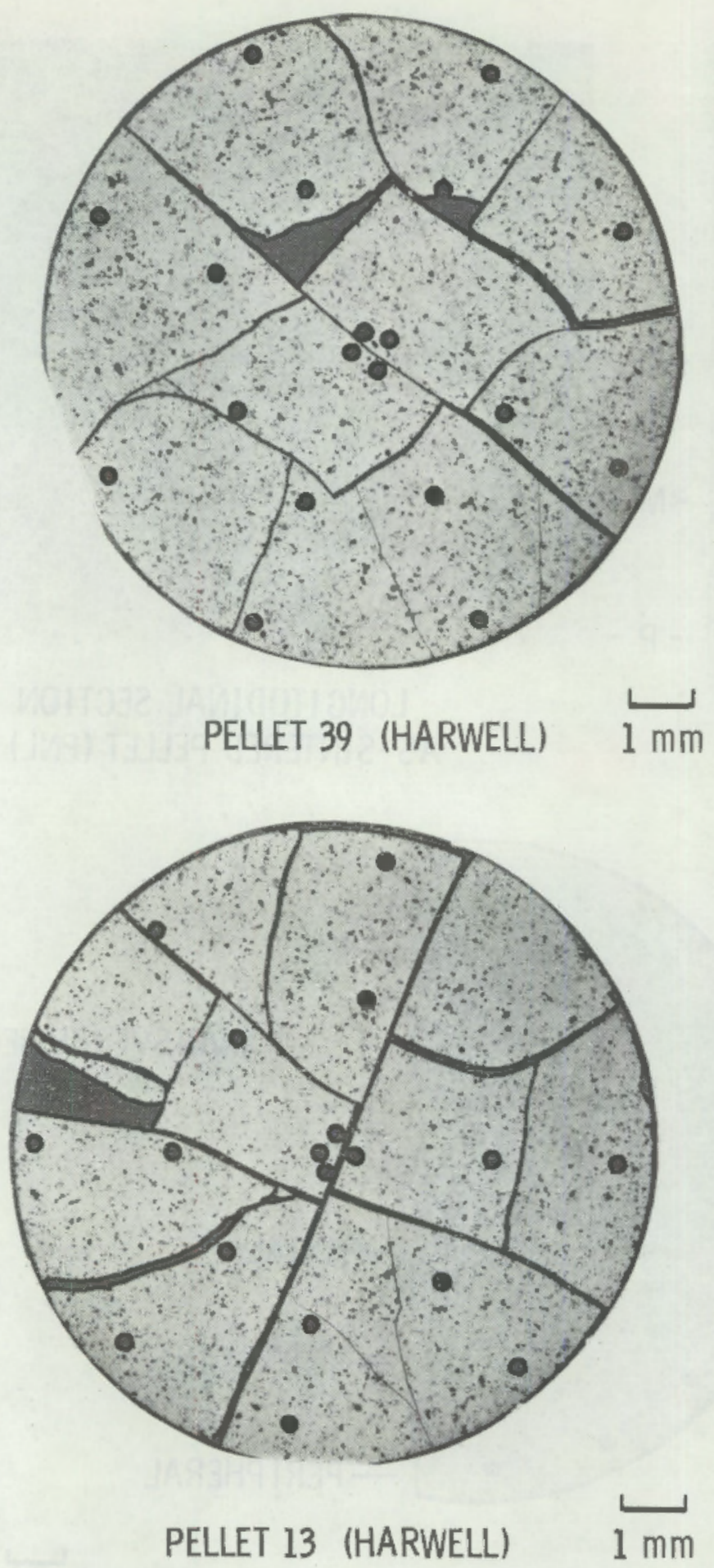

FIGURE 13. Polished Sections of 92\% TD Irradiated Pellets Used for Rod 6 of IFA-431. Locations of photomicrography for study of porosity, microstructure, and grain size are shown. 


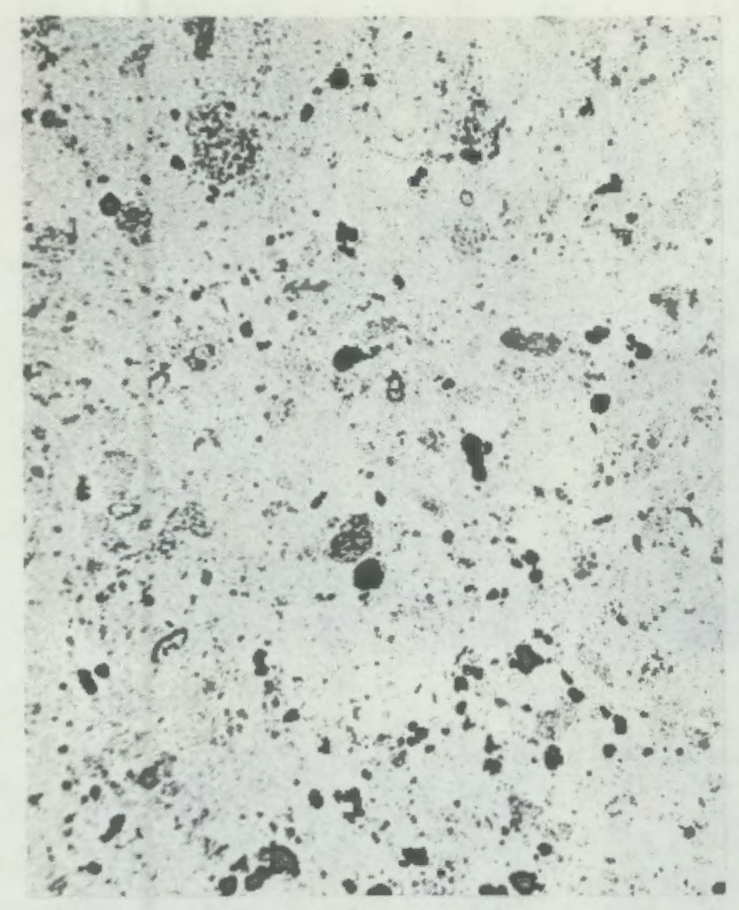

PRECHARACTERIZATION (PNL)

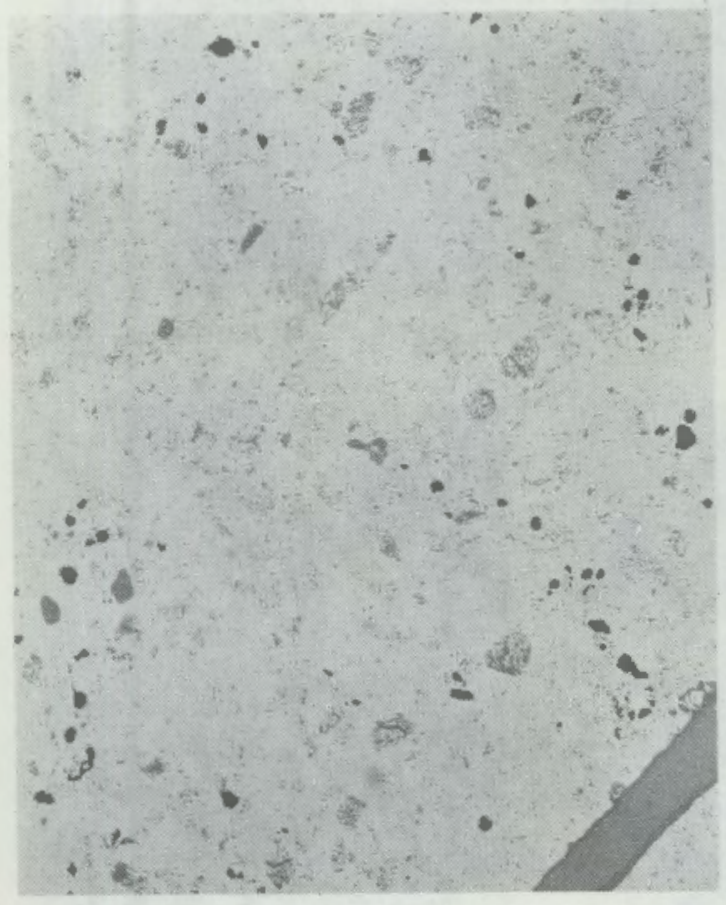

IRRADIATED PELLET 39

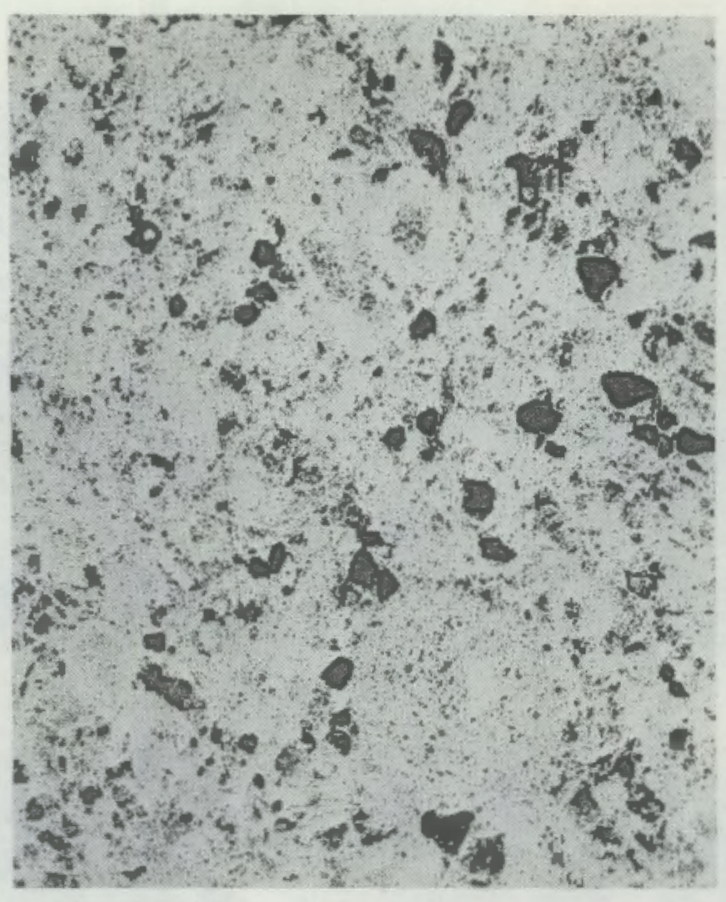

ARCHIVE PELLET (HARWELL)

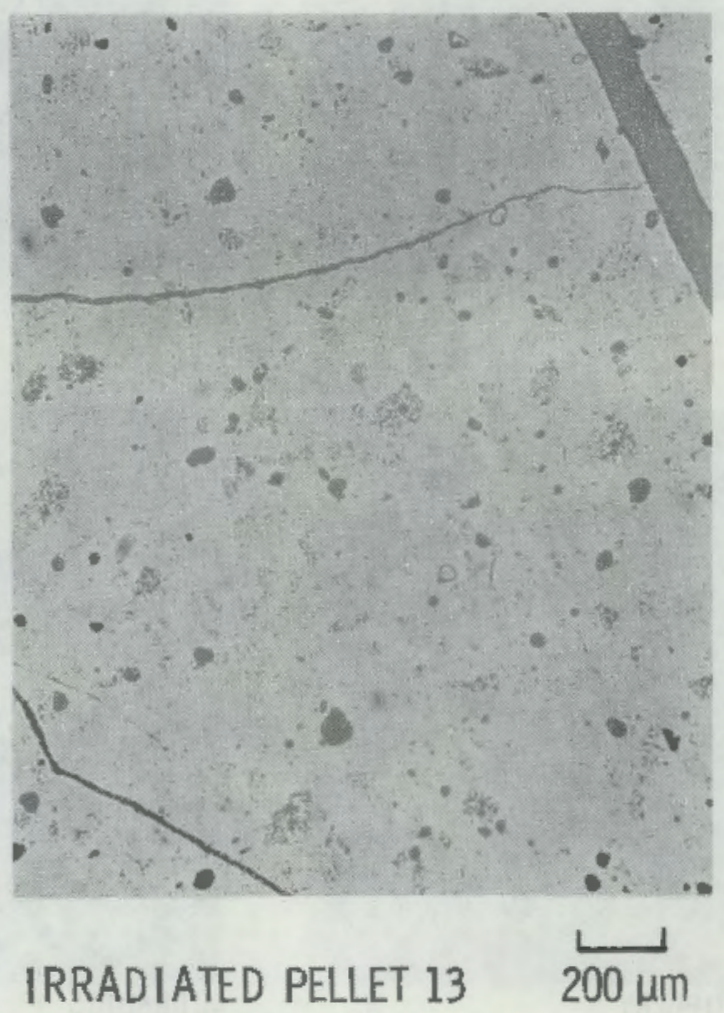

FIGURE 14. Comparison of Polished Sections of As-Sintered and Irradiated Pellets of 92\% TD Fuel 

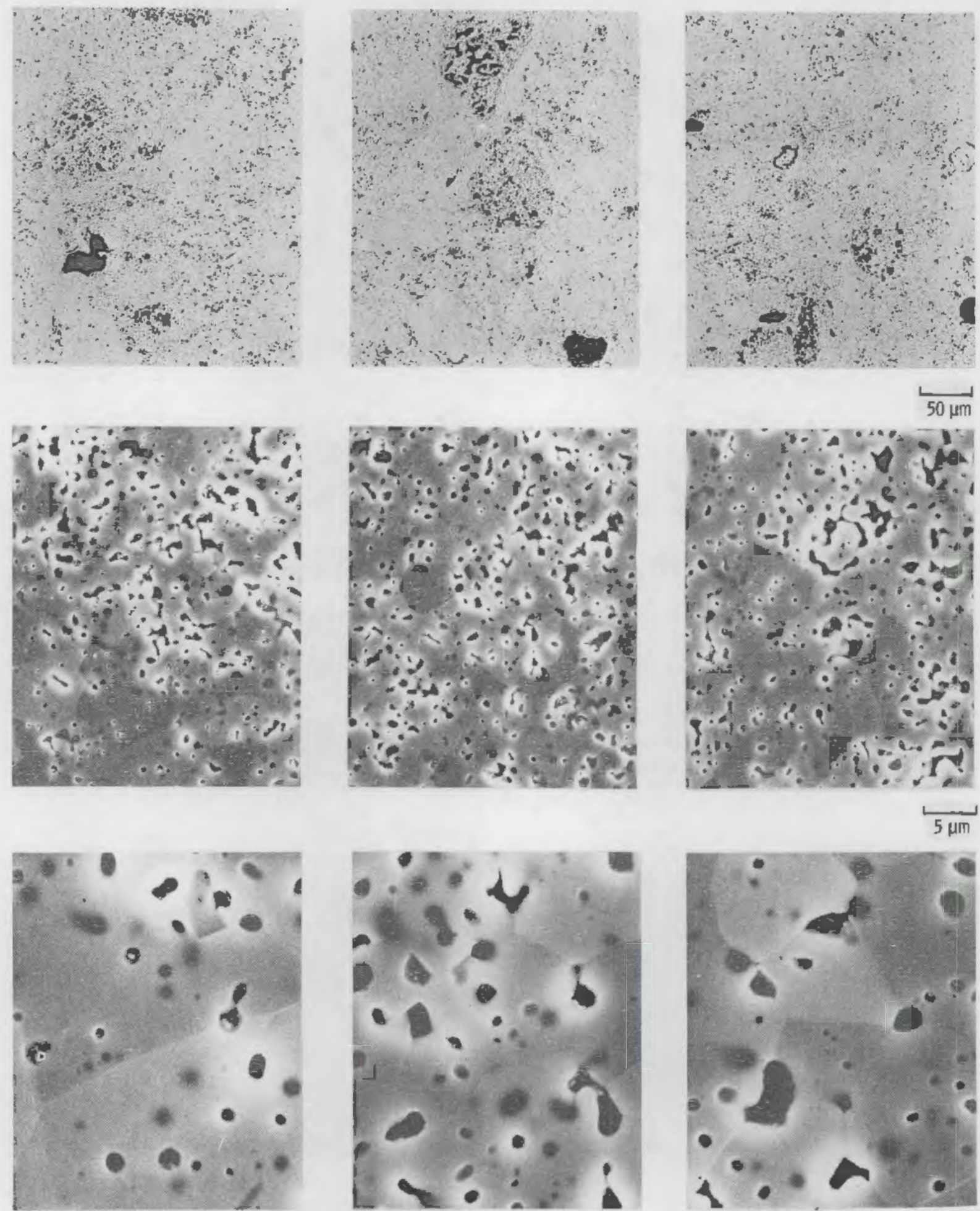

PERIPHERY
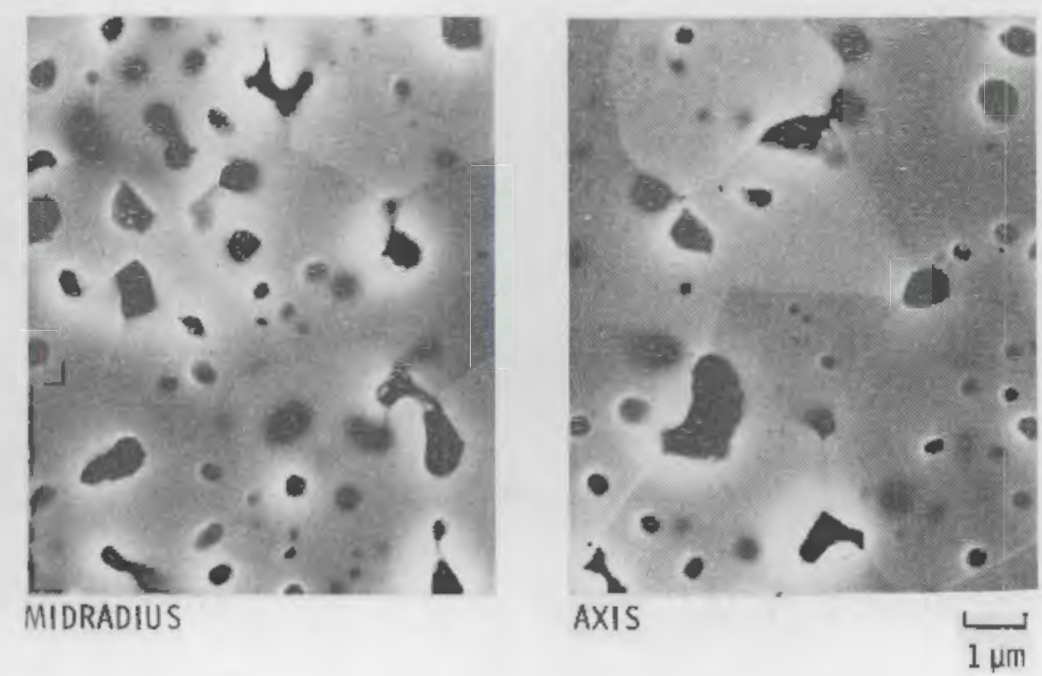

FIGURE 15. Typical Radial Distribution of Porosity of $92 \%$ TD As-Sintered Fuel (polished sections) 

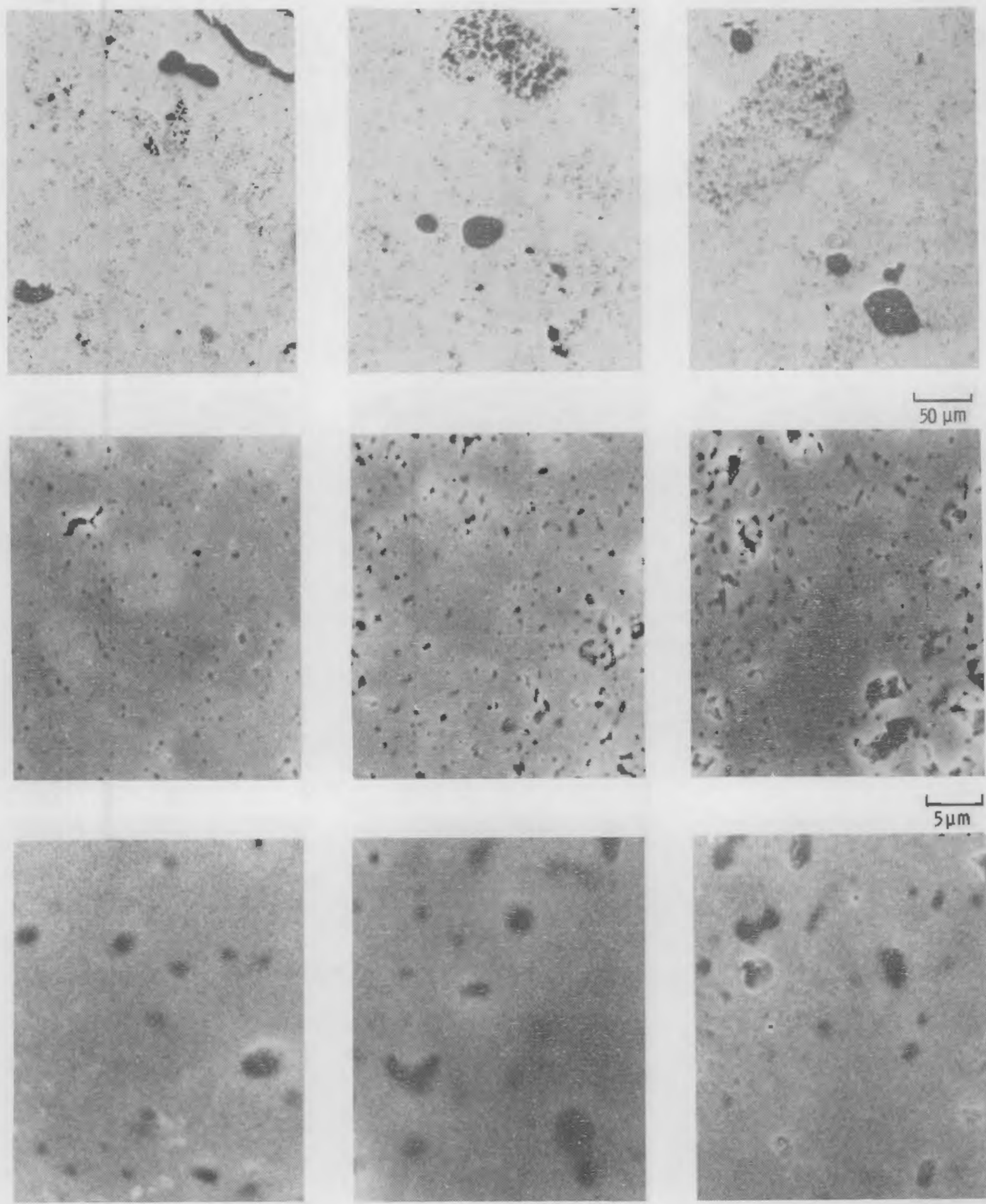

PERIPHERY

MIDRADIUS

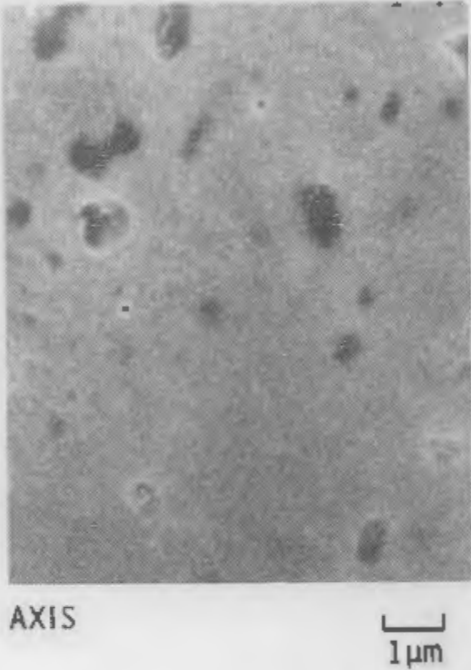

FIGURE 16. Typical Radial Distribution of Porosity of 92\% TD As-Sintered Harwell Archive Fuel Pellet (polished sections) 

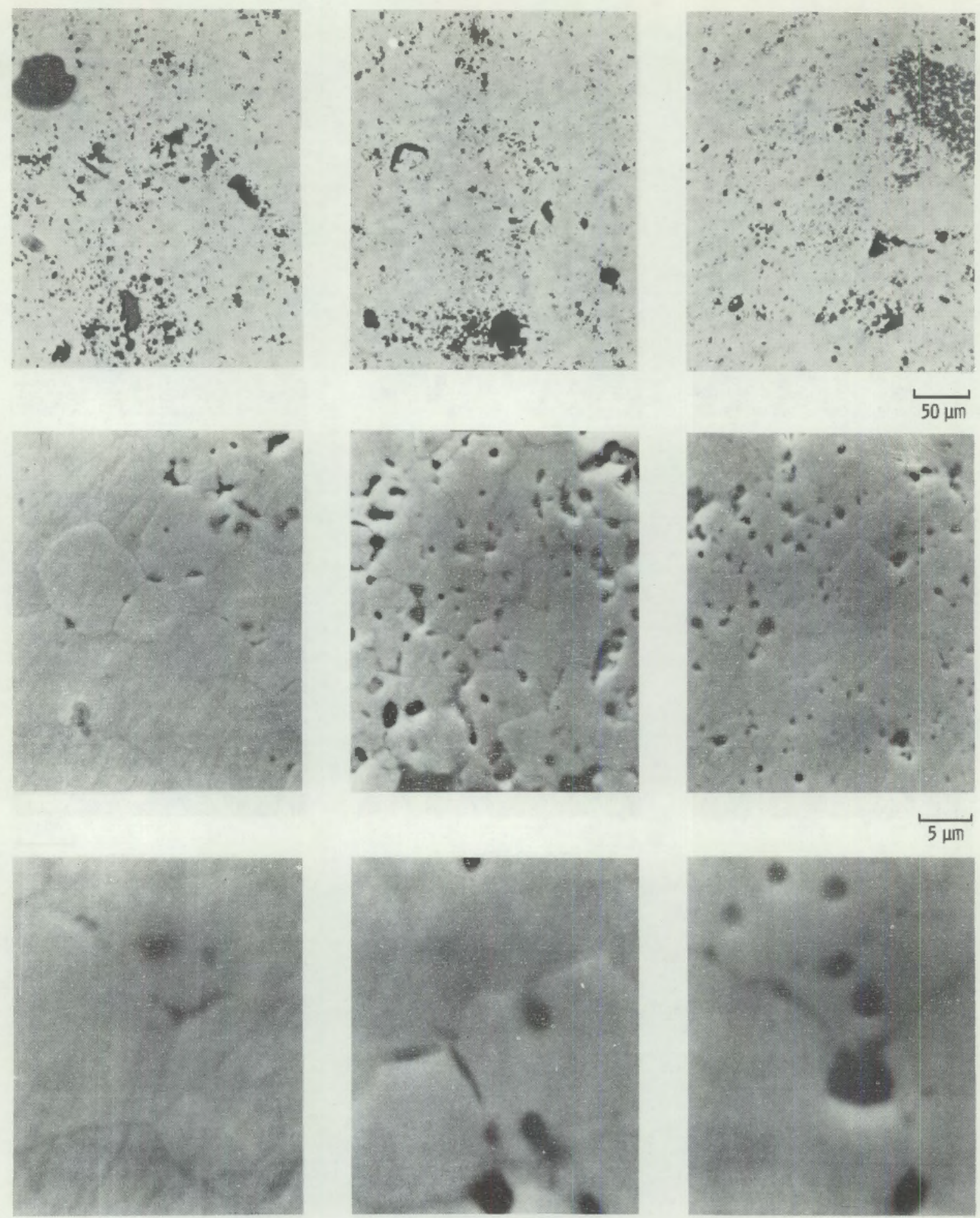

PERIPHERY

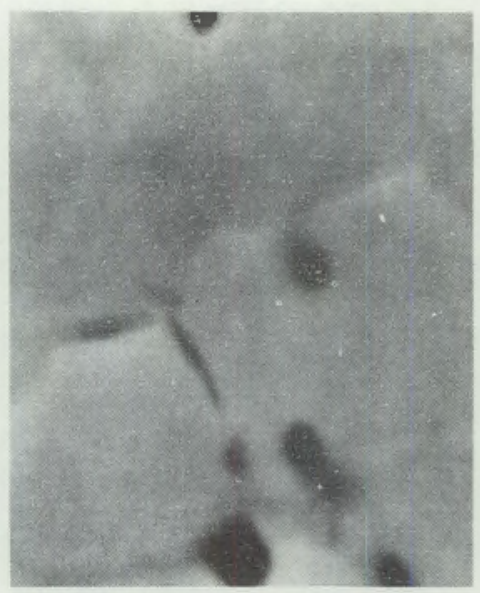

MIDRADIUS

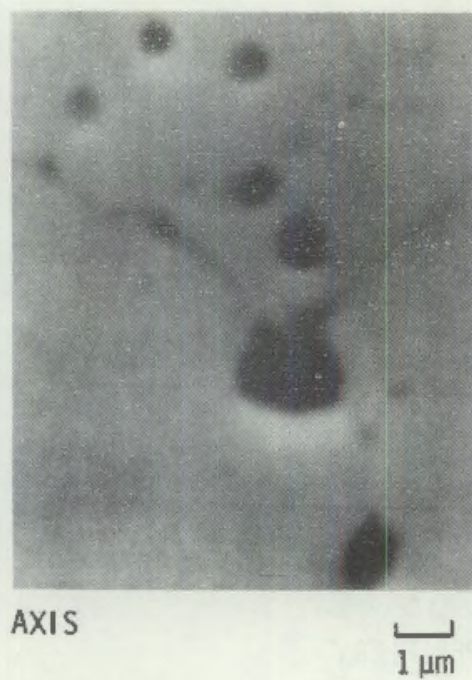

FIGURE 17. Typical Radial Distribution of Porosity of Irradiated Pellet 39 of Rod 6 of IFA-431 (polished sections) 

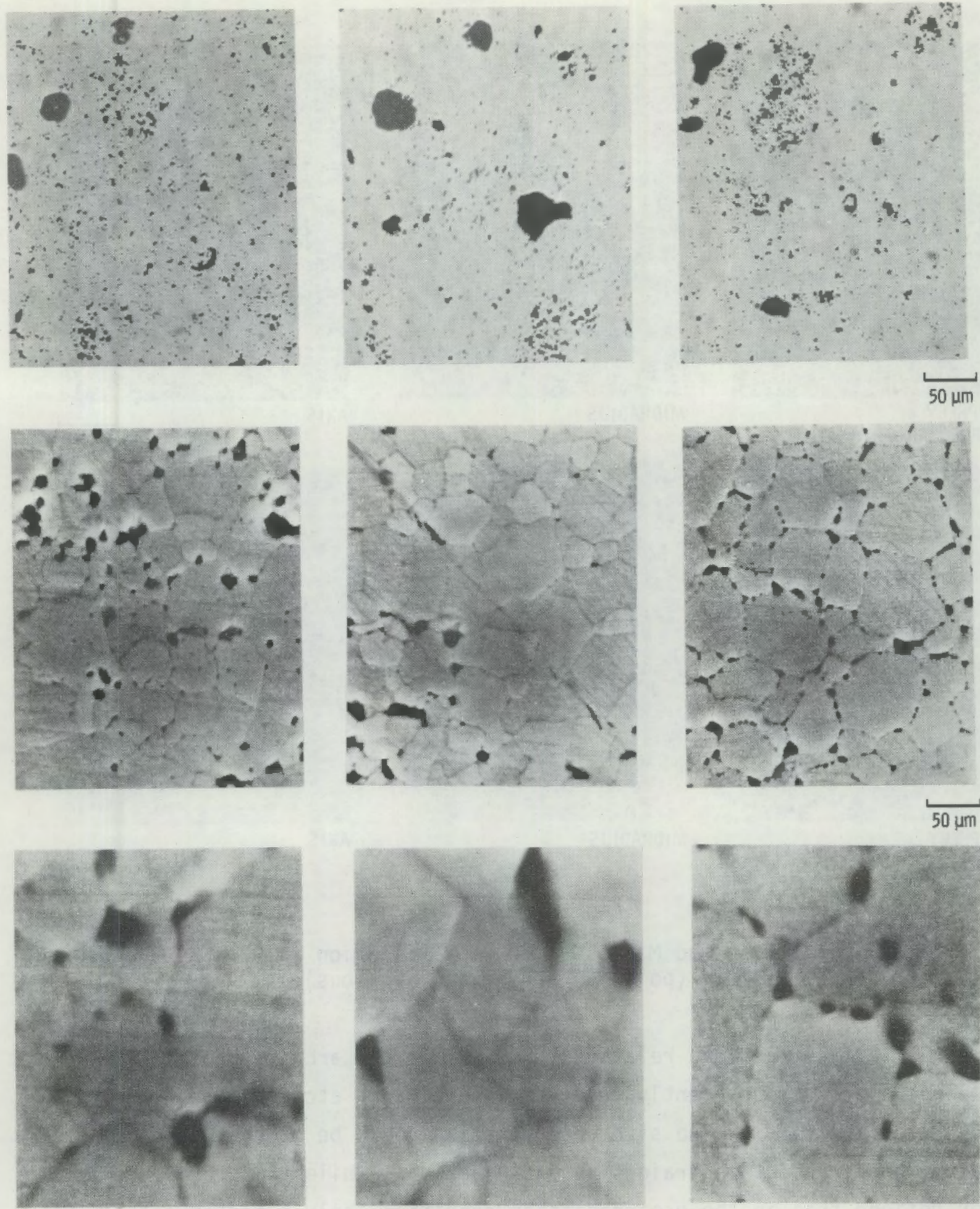

PERIPEHRY

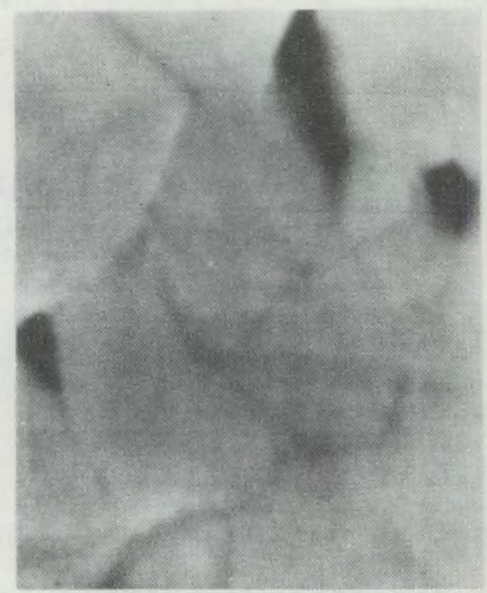

MIDRADIUS

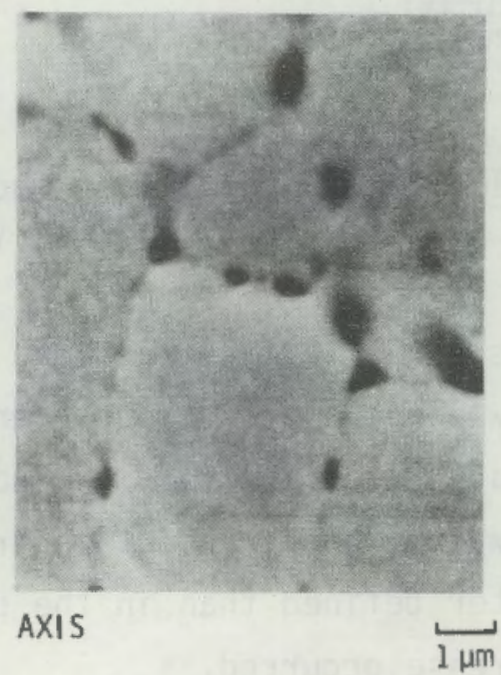

FIGURE 18. Typical Radial Distribution of Porosity of Irradiated Pellet 13 of Rod 6 of IFA-431 (polished sections) 


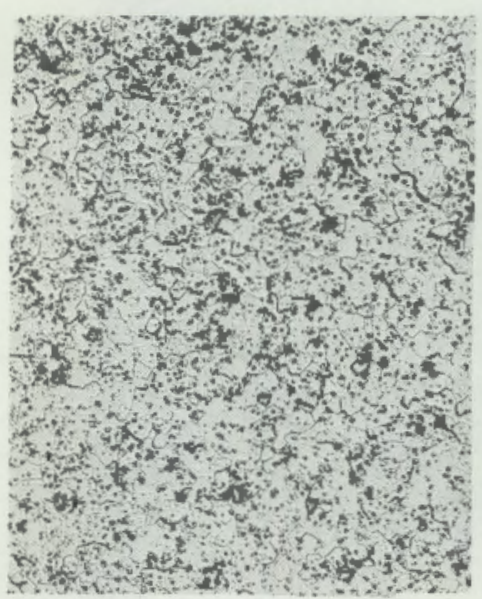

PERIPHERY

PNL PRECHARACTERIZATION

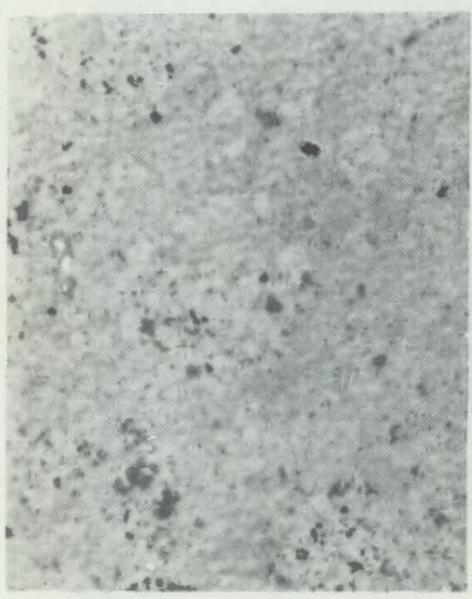

PERIPHERY

HARWELL ARCHIVE PELLET

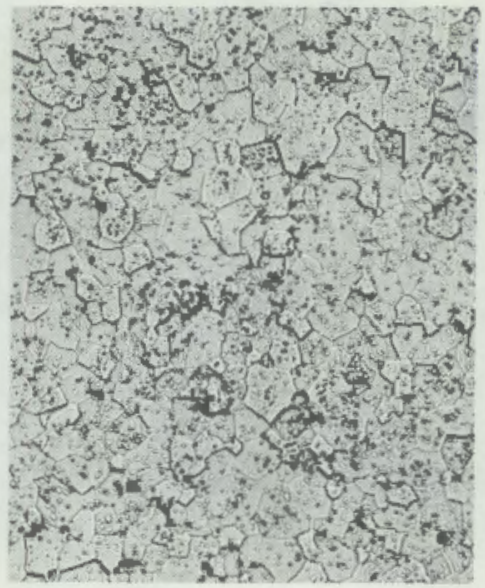

MIDRADIUS

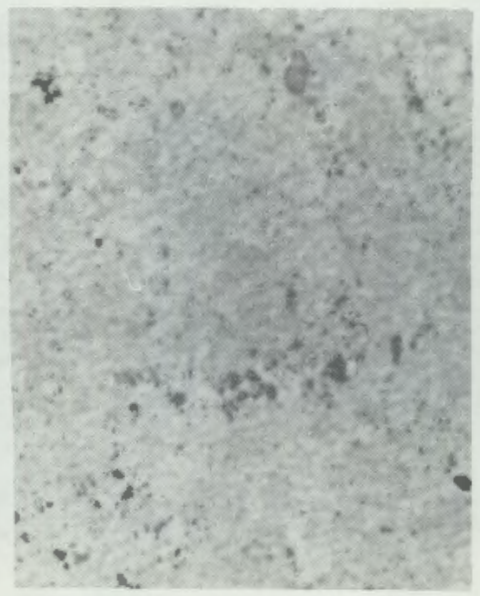

MIDRADIUS
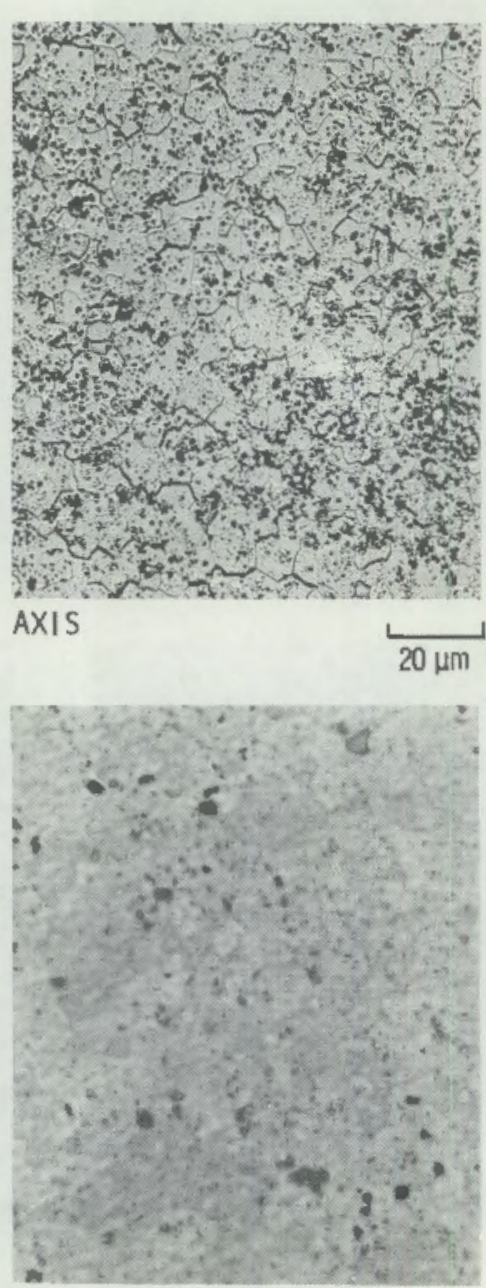

AXIS

$\stackrel{20 \mu \mathrm{m}}{\check{2}}$

FIGURE 19. Grain Size and Microstructure Distribution in 92\% TD As-Sintered Fuel Pellets (polished and etched sections)

reasonably well defined and relatively small. In the archive pellet from Harwe11, the pellets apparently received insufficient etching to define the grains satisfactorily and no size determination could be made. Figure 20 shows the postirradiation grain size distribution. While the grains are much better defined than in the preirradiation condition, only a modest size increase occurred. 


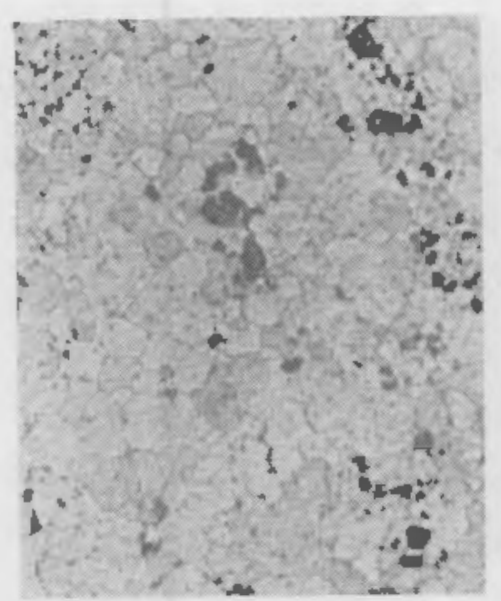

PERIPHERY

PELIET 39

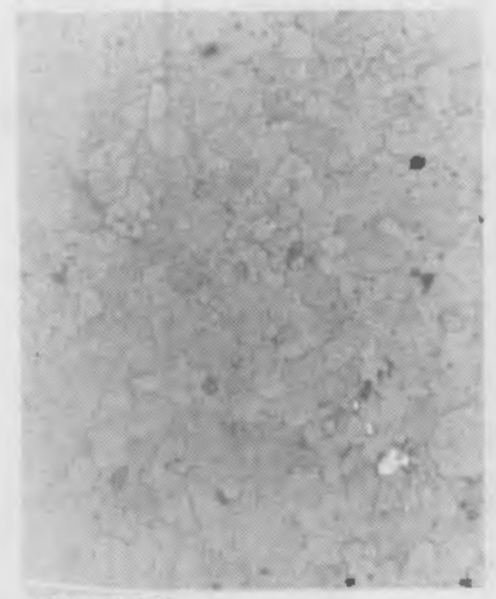

PERIPHERY

PELLET 13

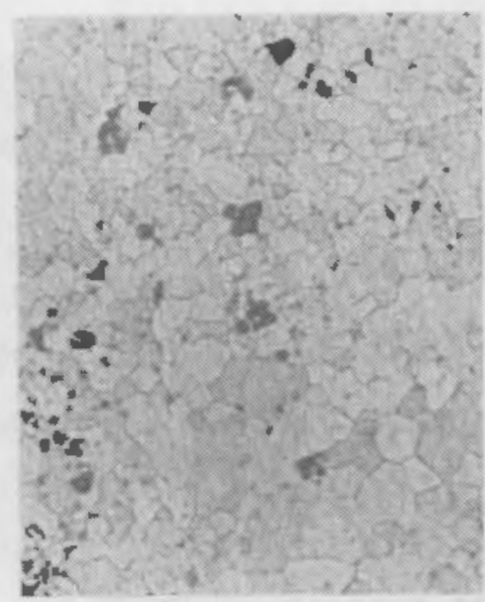

MIDRADIUS

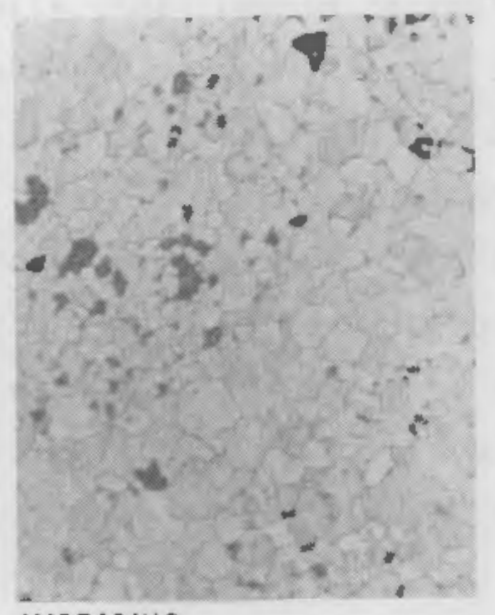

MIDRADIUS
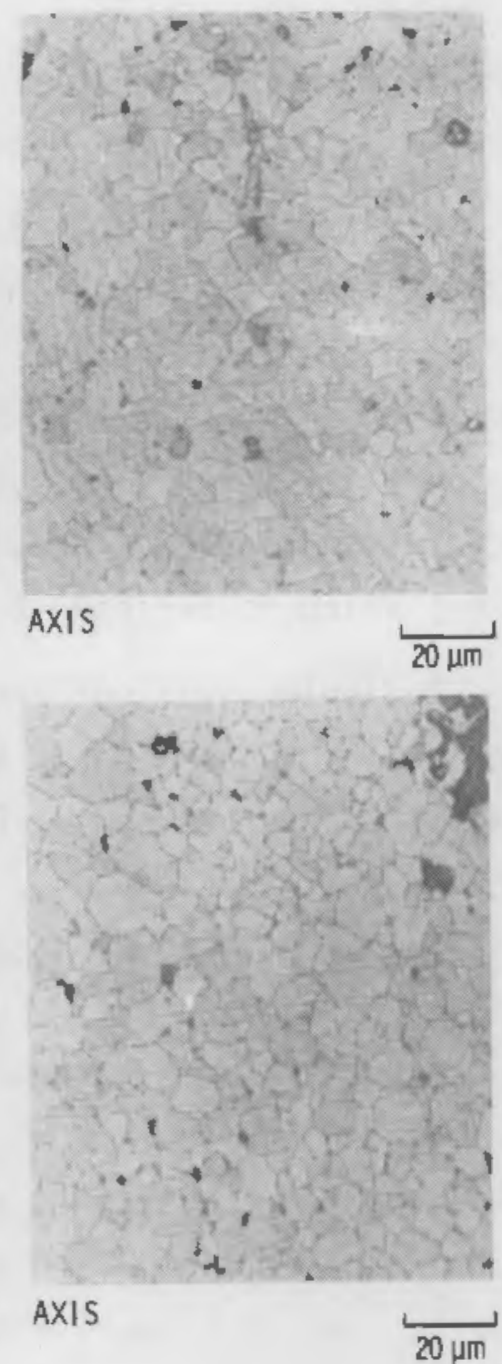

FIGURE 20. Grain Size and Microstructure Distribution in Irradiated Pellets from Rod 6 of IFA-431 (polished and etched sections)

\section{QUANTITATIVE MICROSTRUCTURAL ANALYSIS}

The quantitative examination and measurement of all photomicrographs were conducted using a quantitative image analyzer (Quantimet-720) in the manner described in Reference 12. In this method, each pore in the polished section is examined, its diameter is automatically measured, and these measurements are distributed into size and volume histograms. The three-dimensional volume distribution of the pores within the body of the pellet is estimated from the data using a special computer program (LINEST-II). The assumption is made 
that these pores are spherical and that they are uniformly distributed throughout the pellet volume in the same manner observed for the polished section.

The preirradiation characterizations of fuel pellets examined at PNL and Harwe 11 are compared in Table 3. PNL and Harwell photomicrographs were analyzed on the quantitative image analyzer at PNL. The PNL data showed good agreement between density measurements (made by standard immersion methods) and porosity measurements. Since this fuel type was deliberately prepared as a densifying fuel, it should contain an appreciable fraction of <1-um diameter pores, which is verified by the data in Table 3.

Polishing pull-out problems at Harwell initially resulted in an extremely high pore volume although the total number of pores observed was actually less than that observed in the PNL precharacterization pellet. Upon repolishing the archive pellet at Harwe11, the total volume observed was slightly lower than the nominal 8 to $9 \%$; and pull-out was largely eliminated. Low volume was due largely to the apparent absence of submicrometer porosity; other pore size ranges were in good agreement with the PNL data. The relatively high median pore diameter results from the apparent lack of submicrometer pores. The low submicrometer porosity in the Harwell data apparently resulted from a combination of the polishing method used and inadequate microscope resolution. Subsequent work at Harwell using another scanning electron microscope showed a frequency of submicrometer pores in qualitative agreement with PNL data.

Table 4 shows the effects of irradiation on the porosity characteristics of the fuel pellets from rod 6 , based on image analysis of photomicrographs of the type illustrated in Figures 17 and 18. While the PNL preirradiation immersion density measurements agreed well with the corresponding pore volume measurements, the Harwell postirradiation immersion density of adjacent pellet 40 does not agree with the Quantimet porosity calculations made on pellet 39. However, there is good agreement between the porosity measurements by photomicrographs of pellet 13 and the postirradiation immersion density of adjacent pellet 12. From previous experience at PNL on a variety of fuel materials, it is concluded that quantitative porosity data and the volume of pores determined therefrom are likely to be the better measurements of the density changes that take place throughout the pellet. 
TABLE 3. Comparison of Preirradiation Characterjzation of Typical 92\% TD Fuel Pellets at PNL and Harwe 11 (a)

\begin{tabular}{|c|c|c|c|}
\hline Porosity Volume, \% & $\begin{array}{l}\text { PNL } \\
\frac{\text { Reference Pellet }}{\text { (b) }} \\
\text { Pellet } 1-6-457\end{array}$ & $\begin{array}{r}\text { Harwell } \\
\text { First Polish }\end{array}$ & $\frac{\text { Pellet }(c)}{\text { Second Polish }}$ \\
\hline By Density Measurement & 8.7 & NA $(d)$ & NA \\
\hline By Pore Measurement & $9.1+0.3$ & $20.4 \pm 0.7$ & $6.8 \pm 0.8$ \\
\hline Pores $<1$ um & 3.5 & 3.8 & 1.3 \\
\hline Pores $>1$ um & $5.6 \pm 0.3$ & $16.6 \pm 0.7$ & $5.5 \pm 0.8$ \\
\hline Pores $>10 \mu \mathrm{m}$ & $2.7+0.3$ & $8.9+0.7$ & $2.9+0.8$ \\
\hline
\end{tabular}

Pore Diameter, um

\begin{tabular}{|c|c|c|c|}
\hline Median, all & 1.8 & 4.8 & 4.8 \\
\hline Median, <l $\mu m$ & 0.6 & 0.8 & 0.6 \\
\hline Median, >1 & 8.5 & 24 & 11 \\
\hline Median, >10 $\mu \mathrm{m}$ & 32 & 53 & 40 \\
\hline Maximum & 220 & 101 & 127 \\
\hline
\end{tabular}

Pore Population, no. $1 \mathrm{~cm}^{3}$

$\begin{array}{llll}\text { A1 } 1 \text { Pores } & 1.9 \pm 0.1 \times 10^{12(\mathrm{e})} & 1.1 \pm 0.2 \times 10^{12(\mathrm{f})} & 0.39 \pm 0.04 \times 10^{12}(\mathrm{~g}) \\ \text { Pores }>1 \mu \mathrm{m} & 1.2 \pm 0.1 \times 10^{10} & 3.7 \pm 0.2 \times 10^{10} & 0.59 \pm 0.11 \times 10^{10} \\ \text { Pores }>10 \mu \mathrm{m} & 5.6 \pm 0.7 \times 10^{6} & 3.6 \pm 2.0 \times 10^{6} & 5.8 \pm 0.2 \times 10^{6}\end{array}$

(a) Confidence intervals $=10 \mathrm{SO}$, based on image analysis calculations only.

(b) All sample preparation, microscopy, and image analyses conducted on reference fuel pellet at PNL (see Reference 12).

(c) Sample preparation and microscopy of archive pellet conducted at Harwell; image analys is conducted at PNL using Harwell photomicrographs.

(d) $N A=$ not available; nominal porosity $=8 \%$.

(e) All pores >0.065-um diameter.

(f) All pores $>0.061-u m$ diameter.

(g) All pores >0.108-um diameter. 


\section{TABLE 4. Effects of Irradiation on Porosity Characteristics of}

92\% TD Fuel Pellets from Rod 6 of IFA-431

\begin{tabular}{|c|c|c|c|}
\hline \multirow[b]{2}{*}{ Estimated Burnup, at. $q^{(b)}$} & $\begin{array}{l}\text { PNL Preirradiation(a) } \\
\text { Characterization } \\
\text { (Ident. No. } 457 \text { ) } \\
\end{array}$ & $\begin{array}{r}\text { Irradiated } \\
\text { Rod 6, } \\
\text { Pellet } 39 \\
\text { (Ident. No. 704) } \\
\end{array}$ & $\begin{array}{l}\text { Pellets (a) } \\
\text { Rod 6, } \\
\text { Pellet 13 } \\
\text { (Ident. No. 745) }\end{array}$ \\
\hline & 0 & 0.41 & 0.55 \\
\hline $\begin{array}{l}\text { Approximate Maximum Thermo } \\
\text { couple Temperature, } x\end{array}$ & -- & 1223 & 1523 \\
\hline Porosity volume, $\%$ & & & \\
\hline By Density Measurement & & & \\
\hline Preirradiation (c) & 8.7 & 7.6 & 8.0 \\
\hline Postirradiation (b) & -- & 3.4 & 3.7 \\
\hline By Pore Measurement & $9.1 \pm 0.3$ & $6.1 \pm 0.3$ & $4.1 \pm 0.2$ \\
\hline Pores $<1$ um & 3.5 & 0.5 & 0.5 \\
\hline Pores $>1 \mu m$ & $5.6 \pm 0.3$ & $5.6 \pm 0.3$ & $3.6 \pm 0.2$ \\
\hline Pores $>10 \mu \mathrm{m}$ & $2.7 \pm 0.3$ & $2.2 \pm 0.3$ & $1.8 \pm 0.2$ \\
\hline Pore Diameter, $\mu \mathrm{m}$ & . & & \\
\hline Median, all & 1.8 & 5.4 & 7.1 \\
\hline Median, <1 $\mu \mathrm{m}$ & 0.6 & 0.8 & 0.9 \\
\hline Median, >1 um & 8.5 & 7.0 & 12 \\
\hline Median, $>10 \mu \mathrm{m}$ & 32 & 45 & 45 \\
\hline Maximum & 220 & 111 & 84 \\
\hline Pore Population, $n 0.1 \mathrm{~cm}^{3}$ & & & \\
\hline All Pores & $1.9 \pm 0.1 \times 10^{12(d)}$ & $0.14 \pm 0.04 \times 10^{12(\mathrm{e})}$ & $0.15 \pm 0.04 \times 10^{12(\mathrm{e})}$ \\
\hline Pores $>1$ um & $1.2 \pm 0.1 \times 10^{10}$ & $0.69 \pm 0.05 \times 10^{10}$ & $0.27 \pm 0.01 \times 10^{10}$ \\
\hline Pores $>10$ um & $5.6 \pm 0.7 \times 10^{6}$ & $5.2 \pm 2.5 \times 10^{6}$ & $1.6 \pm 1.9 \times 10^{6}$ \\
\hline
\end{tabular}

(a) Confidence intervals $=1 \sigma$ SO, based on image analysis calculations only.

(b) Burnup and density of adjacent pellets 40 and 12 as measured at Harwell during PIE (see Reference 11).

(c) Immersion density measurements at PNL.

(d) All pores >0.065-um diameter.

(e) All pores $>0.070-\mu m$ diameter. 
Some of the specific features shown in the table are typical of densification behavior. A decrease in the submicrometer pore volume occurs, which is at the same time reflected in the increased median pore diameter. A significant decrease is also observed in the total pore volume, accompanied by a marked decrease in the total pore population, particularly in the case of pellet 13. Comparison of the postirradiation data with the Harwell archive pellet data shown in Table 3 leads to the same conclusions although the relative differences would be somewhat smaller. It can be concluded that in-reactor densification is confirmed.

The details of the pore size and volume relationships for both pre- and postirradiation data are illustrated in Figures 21 and 22 . In Figure 21 , the preirradiation characterization shows a satisfactory similarity between the pellets prepared and examined at PNL and Harwe 11; the differences cited earlier for the total volume of submicrometer porosity are clearly indicated by the size of the peak at that end of the curve. Other components of the curves and pore volume distribution are in close agreement. In Figure 22 the differences between pre- and postirradiation curves are clearly illustrated as is the difference between pellets 13 and 39. With increasing irradiation, the total pore volume in the submicrometer range continued to decrease and the total pore volume in the midrange and larger sizes simultaneously increased. These curves are consistent with the sumnary data described in Tables 3 and 4.

The radial distribution of porosity in the irradiated pellets is sumnarized in Tables 5 and 6 . Harwe 11 measurements of immersion density using small core samples taken from the polished surface of these peliets indicated a density difference across the diameter of the pellet, but these density differences are not confirmed by quantitative image analysis. On each polished cross section, the densities calculated from pore volume are essentially the same across the entire radius. Slight densification might be indicated at the midradius position, but the error bars are too large to confirm that difference. There appears to be a definite trend toward fewer submicrometer pores at the center of the pellet, which is confirmed by the larger median diameter in the center and by the smaller total pore population. The largest pores are near the periphery and the smallest are at approximately midradius. The large standard deviations are due primarily to the relatively few pores present. 

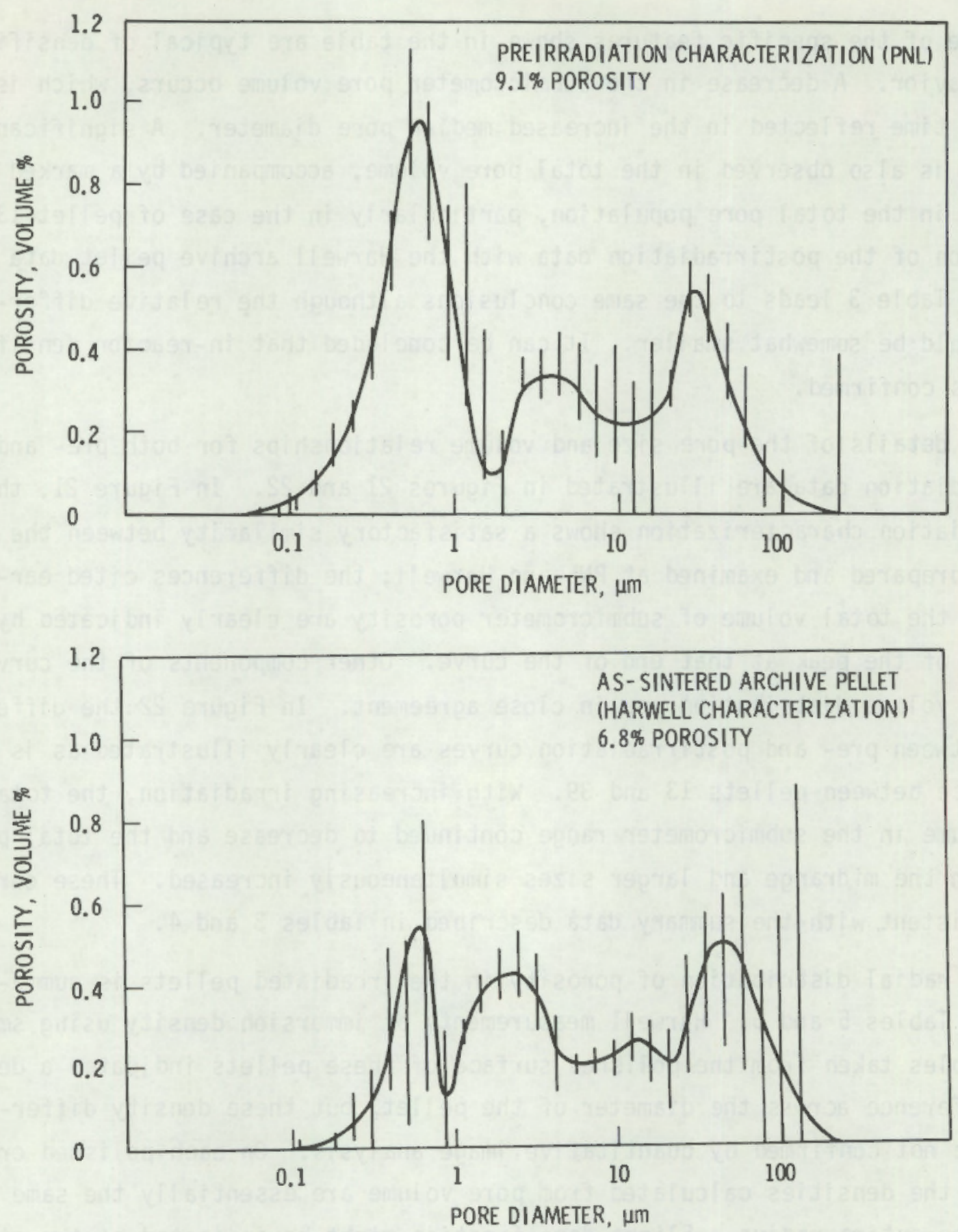

FIGURE 21. Pore Size and Volume Distribution in 92\% TD As-Sintered Pellets (error bars $=2 \sigma \mathrm{SD}$ ) 

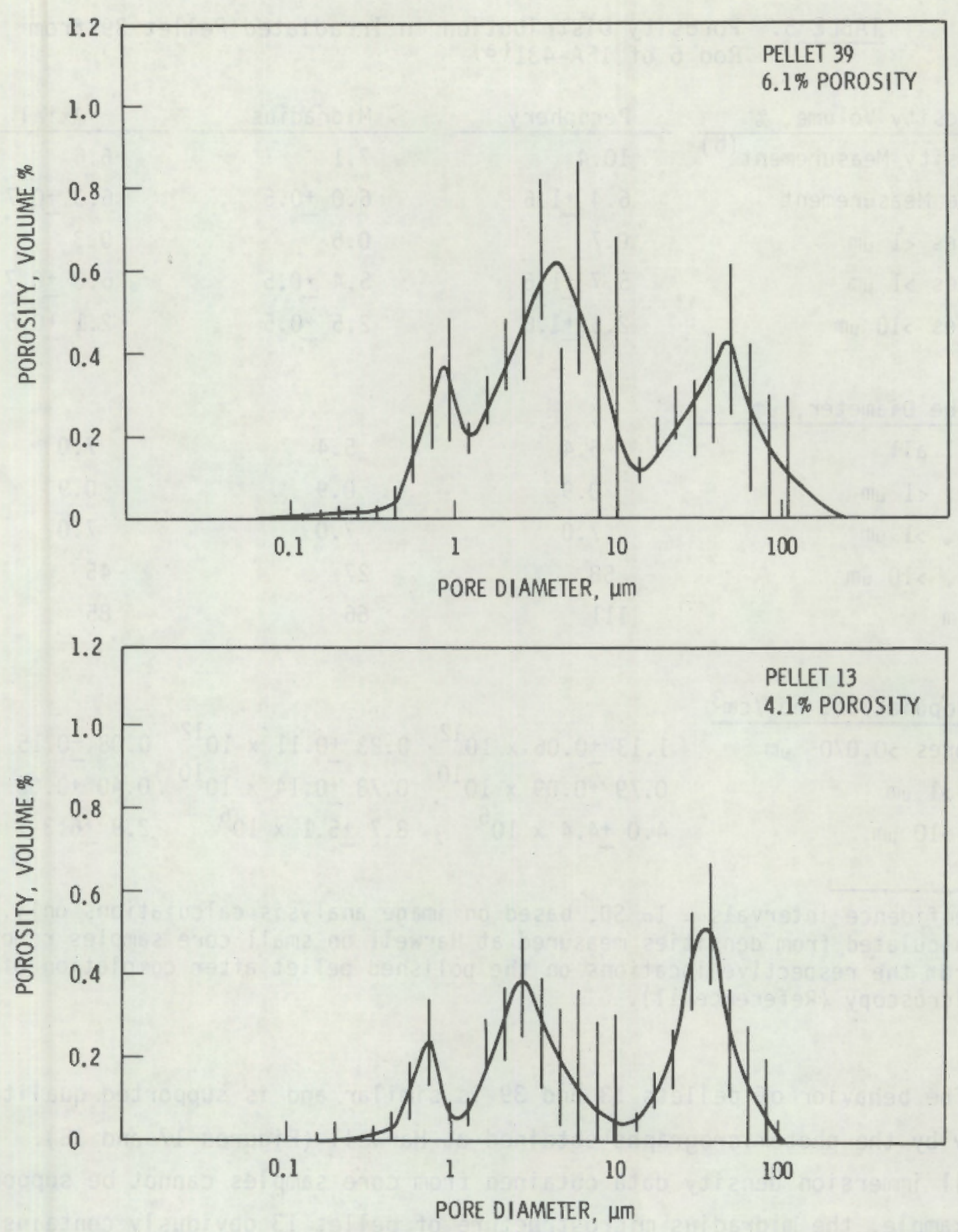

FIGURE 22. Pore Size and Volume Distribution in $92 \%$ TD Irradiated Pellets from Rod 6 of IFA-431 (error bars $=2 \sigma \mathrm{SD}$ ) 
TABLE 5. Porosity Distribution in Irradiated Pellet 39 from Rod 6 of IFA-431(a)

\begin{tabular}{|c|c|c|c|}
\hline Poros ity volume, $\%$ & Periphery & Midradius & Axial \\
\hline By Density Measurement $(b)$ & 10.4 & 7.1 & 6.6 \\
\hline By Pore Measurement & $6.4 \pm 1.6$ & $6.0 \pm 0.5$ & $6.3 \pm 0.7$ \\
\hline Pores $<1 \mu \mathrm{m}$ & 0.7 & 0.6 & 0.3 \\
\hline Pores $>1 \mu \mathrm{m}$ & $5.7 \pm 1.6$ & $5.4 \pm 0.5$ & $6.0 \pm 0.7$ \\
\hline Pores $>10 \mu \mathrm{m}$ & $2.5+1.6$ & $2.5+0.5$ & $2.1+0.6$ \\
\hline
\end{tabular}

\begin{tabular}{lccc}
\multicolumn{1}{c}{ Pore Diameter, $\mu \mathrm{m}$} & & & \\
\cline { 1 - 2 } Median, all & 5.4 & 5.4 & 7.0 \\
Median, <1 $\mu \mathrm{m}$ & 0.9 & 0.9 & 0.9 \\
Median, >1 $\mu \mathrm{m}$ & 7.0 & 7.0 & 7.0 \\
Median, >10 $\mathrm{m}$ & 58 & 27 & 45 \\
Maximum & 111 & 66 & 85
\end{tabular}

Pore Population, no. $1 \mathrm{~cm}^{3}$

$\begin{array}{llll}\text { All Pores }>0.070 \mu \mathrm{m} & 1.13 \pm 0.06 \times 10^{12} & 0.23 \pm 0.11 \times 10^{12} & 0.08 \pm 0.15 \times 10^{12} \\ \text { Pores }>1 \mu \mathrm{m} & 0.79 \pm 0.09 \times 10^{10} & 0.78 \pm 0.14 \times 10^{10} & 0.40 \pm 0.06 \times 10^{10} \\ \text { Pores }>10 \mu \mathrm{m} & 4.0 \pm 4.4 \times 10^{6} & 8.7 \pm 5.1 \times 10^{6} & 2.9 \pm 6.3 \times 10^{6}\end{array}$

(a) Confidence intervals $=10$ SD, based on image analysis calculations only.

(b) Calculated from densities measured at Harwell on small core samples removed from the respective locations on the polished pellet after completion of microscopy (Reference 11).

The behavior of pellets 13 and 39 is similar and is supported qualitatively by the photomicrographs obtained at Harwell (Figures 17 and 18). Harwell immersion density data obtained from core samples cannot be supported. For example, the midradius microstructure of pellet 13 obviously contains more than $0.4 \%$ porosity (see Figure 18 ).

Figure 23 summarizes all the previous data by showing a comparison of the total pore volume and the pore volume distribution in the as-sintered and irradiated pellets. The general relationsinips shown are consistent with the 
TABLE 6. Porosity Distribution in Irradiated Peilet 13 from Rod 6 of IFA-431 (a)

\begin{tabular}{|c|c|c|c|}
\hline Porosity Volume, $\%$ & Periphery & Midradius & Axial \\
\hline By Density Measurement $(\mathrm{b})$ & 7.6 & 0.4 & 6.3 \\
\hline By Pore Measurement & $4.1+0.5$ & $3.9+0.6$ & $4.4+0.5$ \\
\hline Pores $<1 \mu \mathrm{m}$ & 0.5 & 0.2 & 0.8 \\
\hline Pores $>1 \mu m$ & $3.6+0.5$ & $3.7+0.6$ & $3.6 \pm 0.5$ \\
\hline Pores $>10 \mu \mathrm{m}$ & $2.0+0.5$ & $1.9+0.6$ & $1.6+0.5$ \\
\hline
\end{tabular}

\section{Pore Diameter, um $^{\mathrm{m}}$}

Median, all

Median, <l $\mu \mathrm{m}$

Median, >1 $\mu \mathrm{m}$

Median, $>10 \mu m$

Maximum
5.0

0.9

20

45

66

\section{1}

0.9

12

45

86
4.2

0.9

7.1

35

51

Pore Population, $n 0.1 \mathrm{~cm}^{3}$
All Pores $>0.070 \quad \mu \mathrm{m}$
$0.12+0.05 \times 10^{12}$
$0.25+0.14 \times 10^{12}$
$0.20 \pm 1.4 \times 10^{12}$
Pores $>1 \mu \mathrm{m}$
$0.33+0.02 \times 10^{10}$
$0.18+0.01 \times 10^{10}$
$0.30 \pm 0.02 \times 10^{10}$
Pores $>10 \mu \mathrm{m}$
$0.86 \pm 5.6 \times 10^{6}$
$2.2+5.4 \times 10^{6}$
$1.8+5.9 \times 10^{6}$

(a) Confidence intervals $=10$ SD, based on image analys is calculations only.

(b) Calculated from densities measured at Harwell on small core samples removed from the respective locations on the polished pellet after completion of microscopy (Reference 11).

conclusions that densification clearly occurred in pellets 13 and 39 . While the difference between the precharacterization pellets observed at PNL and the archive pellet observed at Harwell is disturbing, the probable explanation given earlier (that the smail pores present were not satisfactorily observed at Harwe11) still appears applicable. In any case, the differences observed in the irradiated pellets (whether compared to PNL or Harwell precharacterization information) are still reasonable and consistent within the data set. 


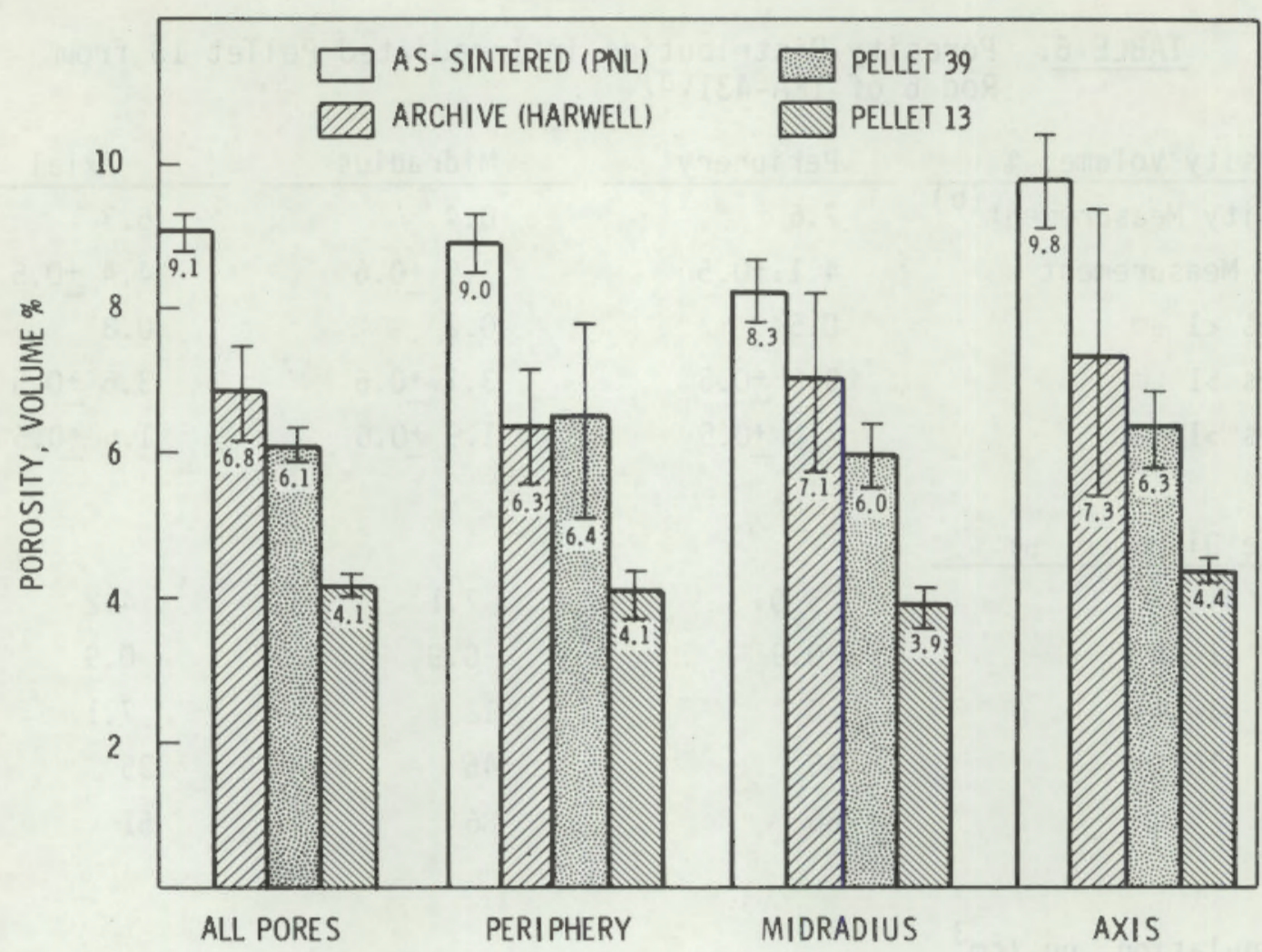

FIGURE 23. Comparison of Total Pore Volume and Pore Volume Distribution in 92\% TD As-Sintered and Irradiated Pellets

The pore population relationship between and within preirradiation and irradiated pellets is illustrated in Figures 24 and 25 . Previously discussed data from Tables 3 and 4 applies.

To obtain grain size information, the pellets were subsequently etched specifically for grain size definition; measurements were made by the linear intercept technique used in previous work. Table 7 summarizes the measurements from photomicrographs of the type illustrated in Figures 19 and 20. The resulting grain size in the irradiated pellets is only slightly increased or unchanged from preirradiation dimensions. The grain size increase certainly did not approach that achieved in the resintering tests applied to the similar fuel type. From that observation it $c$ an be concluded that the temperature within pellets 13 and 39 did not approach the 1873 or 1973K applied in the resintering tests. 


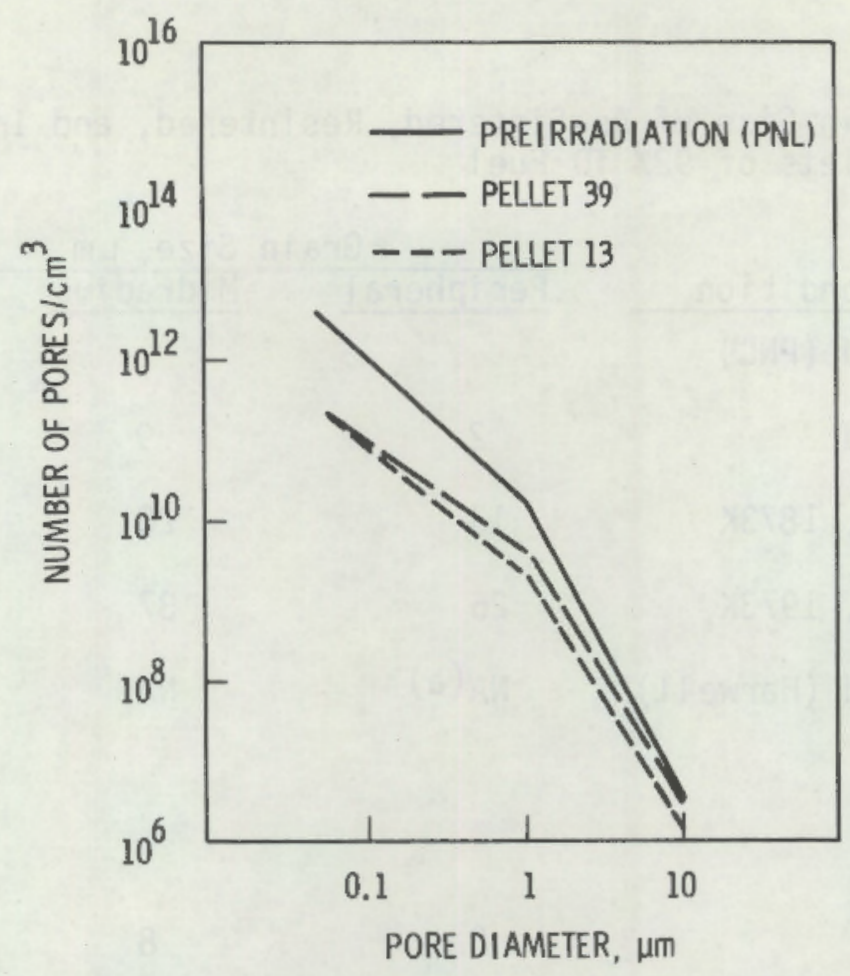

FIGURE 24. Change in Cumulative Pore Population of $92 \%$ TD Pellets During Irradiation
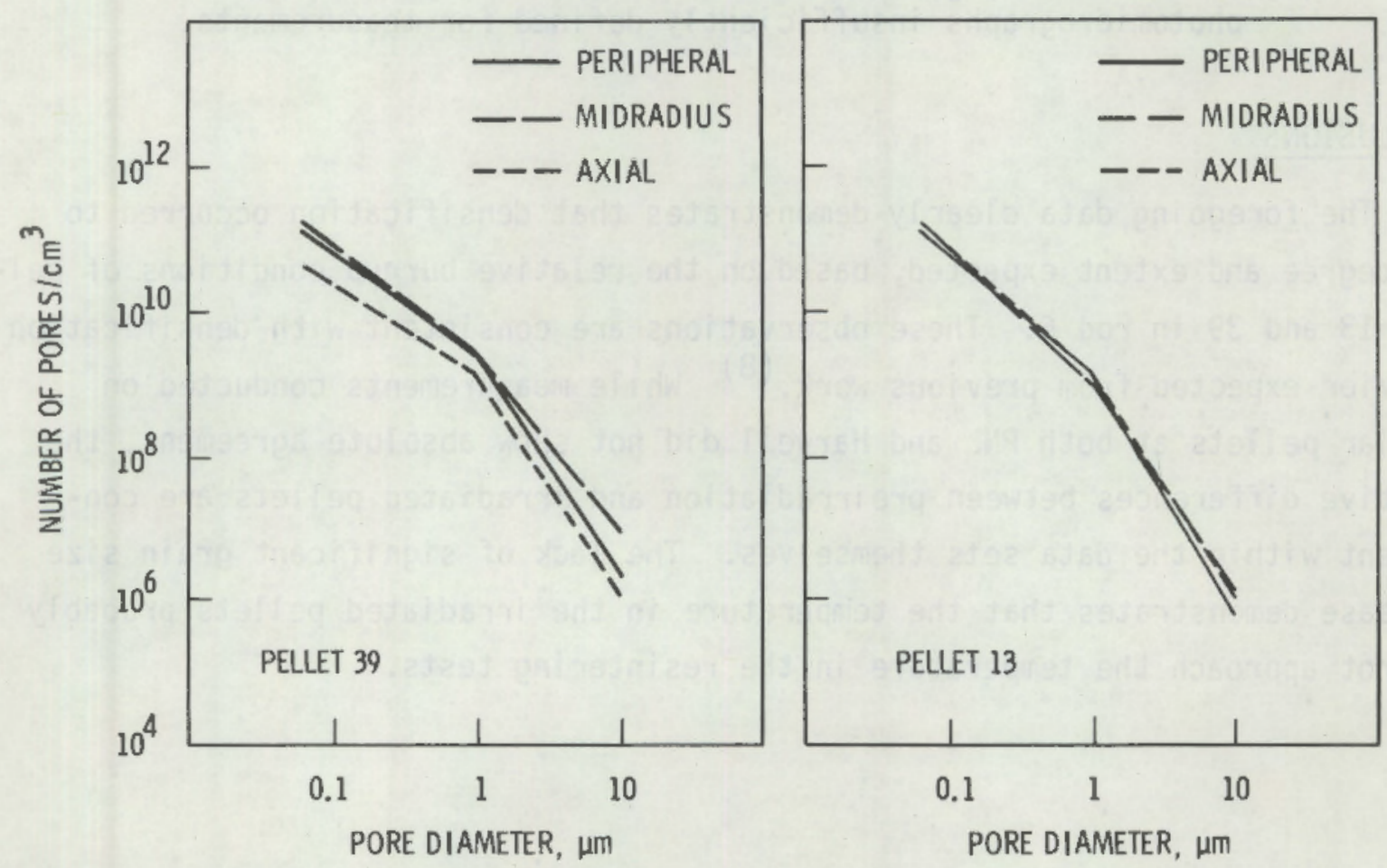

FIGURE 25. Radial Distribution of Pore Population of 92\% TD Irradiated Pellets 
TABLE 7. Grain Size of As-Sintered, Resintered, and Irradiated Pellets of $92 \%$ TD Fuel

\begin{tabular}{|c|c|c|c|c|}
\hline \multirow{2}{*}{\multicolumn{2}{|c|}{ Specimen Condition }} & \multicolumn{3}{|c|}{ Grain Size, $\mu \mathrm{m}$} \\
\hline & & Peripheral & Midradius & Axial \\
\hline \multicolumn{5}{|c|}{ Preirradiated (PNL) } \\
\hline As-Sintered & & 2 & 9 & 7 \\
\hline Resintered, & $1873 \mathrm{~K}$ & 13 & 20 & 15 \\
\hline Resintered, & 1973K & 26 & 37 & 53 \\
\hline Preirradiated & (Harwe 11) & NA(a) & NA & NA \\
\hline Archive & & & & \\
\hline \multicolumn{5}{|l|}{ Irradiated } \\
\hline Pellet 39 & & 8 & 8 & 8 \\
\hline Pellet 13 & & 7 & 7 & 8 \\
\hline
\end{tabular}

\section{CONCLUSIONS}

The foregoing data clearly demonstrates that densification occurred to the degree and extent expected, based on the relative burnup conditions of pellets 13 and 39 in rod 6 . These observations are consistent with densification behavior expected from previous work. (8) While measurements conducted on similar pellets at both PNL and Harwell did not show absolute agreement, the relative differences between preirradiation and irradiated pellets are consistent within the data sets themselves. The lack of significant grain size increase demonstrates that the temperature in the irradiated pellets probably did not approach the temperature in the resintering tests. 


\section{COMPUTER CODE COMPARISONS TO THERMAL DATA}

Because densification has been observed to affect the thermal and mechanical performance of fuel rods, it is important that computer codes used for design and safety studies be able to model densification effects adequately. It is therefore of interest to compare the data from rod 6 of IFA-431 to fuel rod thermal performance computer code calculations. For this comparison, the following codes used by the NRC were selected: GAPCON-THERMAL-3 (GT3), (14) FRAPCON-1, (15) and FRAPCON-2 (Version 1, Mod 2). (16) Of principal consideration is the comparison of calculated centerline temperatures to those measured in-reactor.

The input for fuel thermal performance codes generally consists of fuel rod dimensions, material properties (including initial fuel density), and operating conditions (power and coolant). When comparing the codes to data, initial dimensions, material properties, and coolant conditions are usually fairly well known. The most difficult problem is supplying the code with an appropriate power history based on the as-measured history.

The as-measured power history for rod 6 of IFA-431 is presented in Figure 26 as a function of time at power (i.e., time at shutdown is not included). The solid line in the figure is the selected power history to be used during the data/code comparison. The centerline temperatures corresponding to the power history are presented in Figure 27. The solid line in this figure is the temperature history to be compared to the code results. The selected power history and corresponding centerline temperatures are listed in Table 8.

Additional input parameters that are needed and common to all three codes of interest are listed in Täble 9. Two of the codes--GT3 and FRAPCON-2--allow user input to control the amount of densification calculated during code operation; this input is based on observed densification changes. Two density changes have been observed for the $92 \%$ TD unstable fuel used in rod 6 .

- During the fuel precharacterization for IFA-431/432, (12) an average final density of $95.3 \%$ TD was observed after resintering at $1973 \mathrm{~K}$ for $24 \mathrm{~h}$.

- PIE showed an average final density of $96.5 \%$ TD. 


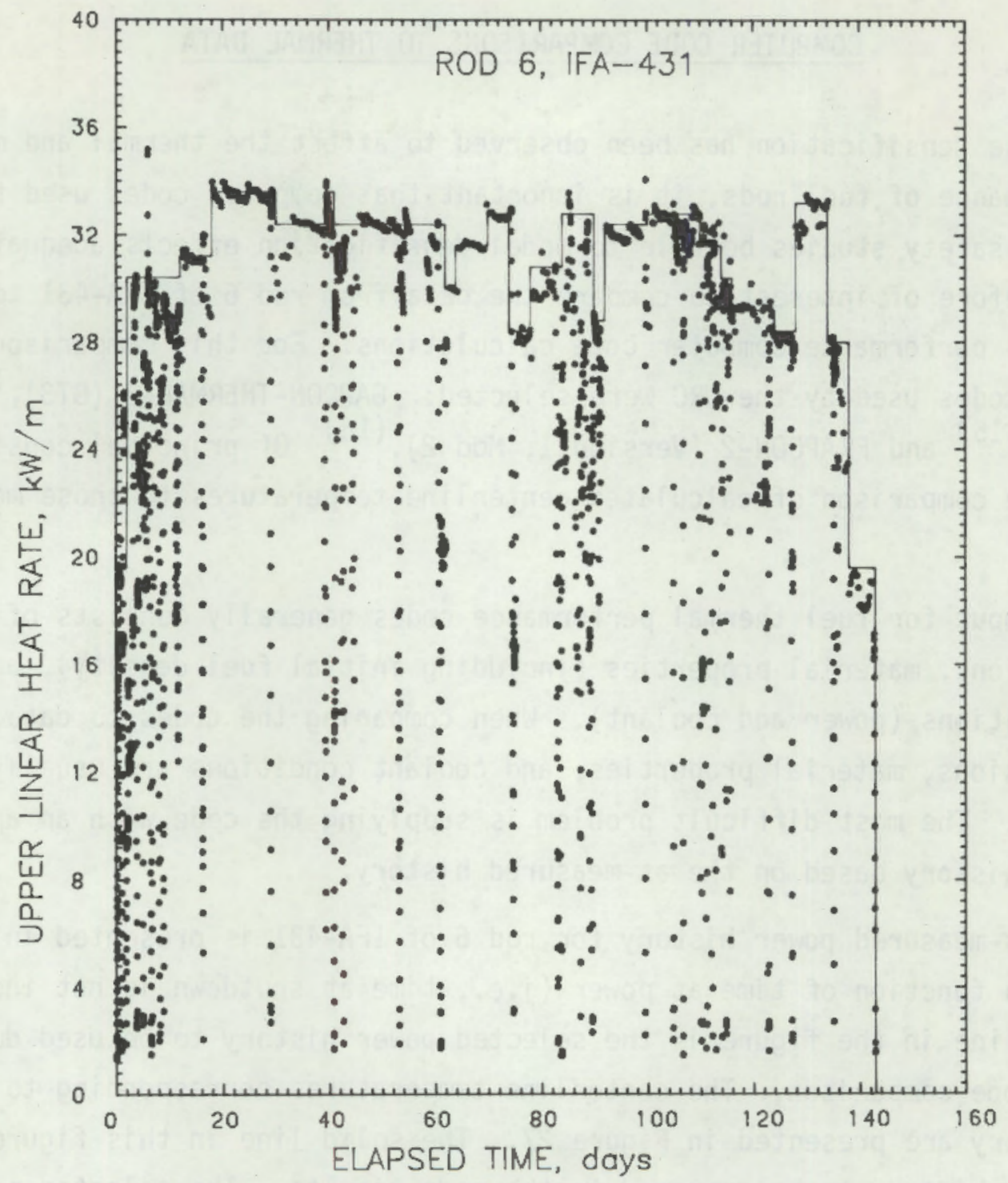

FIGURE 26. Actual Power History and Power History Used for Code Comparison

Densification in GT3 is controlled by inputting the final density, using the time-dependent model of Meyer ${ }^{(10)}$ to apply densification. Three GT3 calculations will be compared to the data: no densification (input variable $\operatorname{FRDEN2}^{(a)}=92 \%$ ), final densification equal to that observed from the thermal resintering tests (FRDEN2 $=95.3 \%$ ), and final densification equal to that observed from PIE (FRDEN2 $=96.5 \%$ ).

(a) Input variable FRDEN is used for the initial density and is equal to $92 \%$ for these calculations; FRDEN2 specifies the density after densification is complete. 


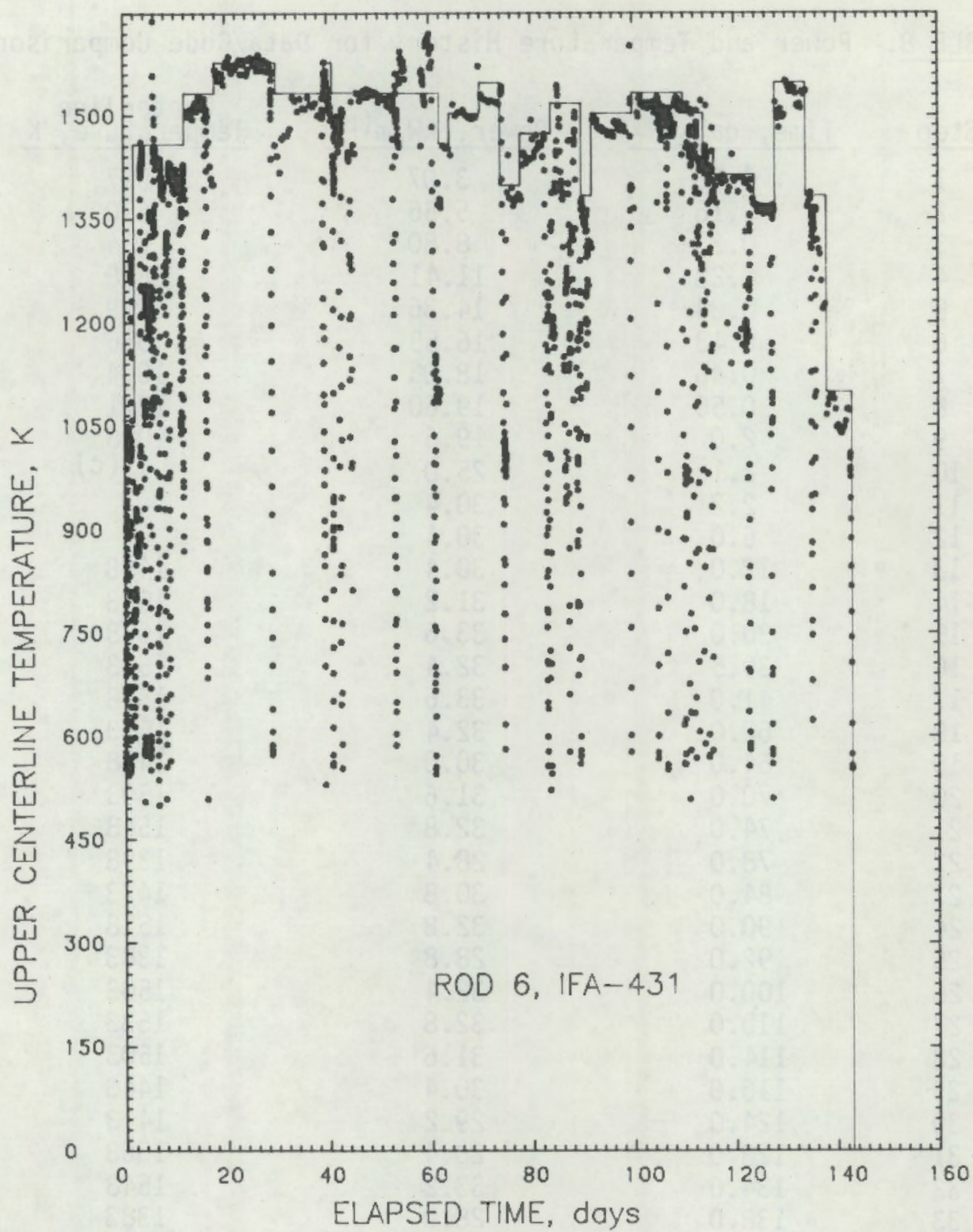

FIGURE 27. Actual Temperature History and Temperature History Used for Code Comparison

Densification in FRAPCON-2 is calculated by the MATPRO ${ }^{(17)}$ routine FUDENS using either the initial density and sintering temperature or the observed density change during a 1973K 24-h resintering test; the second method is recommended. The observed density of $95.3 \%$ TD after resintering at $1973 \mathrm{~K}$ for $24 \mathrm{~h}$ is equivalent to a density increase of $362 \mathrm{~kg} / \mathrm{m}^{3}$ (input variable RSNTR). 
TABLE 8. Power and Temperature History for Data/Code Comparison

\begin{tabular}{|c|c|c|c|}
\hline Step & Time, days (a) & Power, $\mathrm{kW} / \mathrm{m}(\mathrm{b})$ & $\begin{array}{l}\text { Centerline } \\
\text { Temperature, } \mathrm{K}\end{array}$ \\
\hline 1 & 0.08 & 3.07 & 597 \\
\hline 2 & 0.16 & 5.66 & 670 \\
\hline 3 & 0.23 & 8.80 & 764 \\
\hline 4 & 0.28 & 11.41 & 828 \\
\hline 5 & 0.34 & 14.36 & 899 \\
\hline 6 & 0.43 & 16.58 & 956 \\
\hline 7 & 0.46 & 18.05 & 1004 \\
\hline 8 & 0.50 & 19.60 & 1041 \\
\hline 9 & 2.0 & 19.6 & 1058 \\
\hline 10 & 2.1 & 25.0 & -- (c) \\
\hline 11 & 2.2 & 30.4 & -- \\
\hline 12 & 6.0 & 30.4 & -- \\
\hline 13 & 12.0 & 30.4 & 1458 \\
\hline 14 & 18.0 & 31.2 & 1533 \\
\hline 15 & 30.0 & 33.6 & 1578 \\
\hline 16 & 39.5 & 32.4 & 1533 \\
\hline 17 & 41.0 & 33.6 & 1578 \\
\hline 18 & 62.0 & 32.4 & 1533 \\
\hline 19 & 64.0 & 30.0 & 1458 \\
\hline 20 & 70.0 & 31.6 & 1503 \\
\hline 21 & 74.0 & 32.8 & 1548 \\
\hline 22 & 78.0 & 28.4 & 1398 \\
\hline 23 & 84.0 & 30.8 & 1473 \\
\hline 24 & 90.0 & 32.8 & 1518 \\
\hline 25 & 92.0 & 28.8 & 1383 \\
\hline 26 & 100.0 & 32.4 & 1503 \\
\hline 27 & 110.0 & 32.8 & 1533 \\
\hline 28 & 114.0 & 31.6 & 1503 \\
\hline 29 & 116.0 & 30.4 & 1443 \\
\hline 30 & 124.0 & 29.2 & 1413 \\
\hline 31 & 128.0 & 28.4 & 1368 \\
\hline 32 & 134.0 & 33.2 & 1548 \\
\hline 33 & 138.0 & 28.0 & 1383 \\
\hline 34 & 143.0 & 19.6 & 1098 \\
\hline
\end{tabular}

(a) Time, power, and temperature are for the end of each step.

(b) Steps 1 through 8 are taken from startup data; steps 9 through 34 are taken from Figures 26 and 27.

(c) Steps 10 through 12 are necessary for code operation and were not compared to the data. 
TABLE 9. Cormon Input Parameters for Data/Code Comparison

Fuel Dimensions:

cladding outer diameter $\quad 12.79 \mathrm{~mm}$

cladding inner diameter $\quad 10.91 \mathrm{~mm}$

fuel diameter $\quad 10.68 \mathrm{~mm}$

fuel length $\quad 571.5 \mathrm{~mm}$

plenum volume $\quad 1.64 \mathrm{~cm}^{3}$

Materia7s:

initial $\mathrm{UO}_{2}$, density $\quad 92 \%$ TD

$235 \mathrm{U}$ enrichment $\quad 10 \%$

fill gas $100 \%$ He at $0.1 \mathrm{MPa}$

Operating Conditions:

coolant temperature $\quad 513 \mathrm{~K}$

coolant pressure $\quad 3.4 \mathrm{MPa}$

axial power profile see Reference 12

power history see Table 8

FRAPCON-2 contains three mechanical response packages, which complicates its comparison to the data. (a) Each package has a different effect on calculated temperatures and implements the densification calculated by FUDENS differentiy. Thus, to implement the densification options and the mechanical package options, three densification assumptions were combined with the PELET and FRACAS-2 mechanical packages: no densification, densification based on the thermal resintering data (RSNTR $\left.=362 \mathrm{~kg} / \mathrm{m}^{3}\right)$, and densification based on the sintering temperature (RSNTR $\left.=0 \mathrm{~kg} / \mathrm{m}^{3}\right)$. The series of calculations that were made are summarized in Table 10.

(a) FRAPCON-2 is a cooperative effort between PNL and the Idaho National Engineering Laboratory (INEL). Each laboratory has developed its own model of fuel rod mechanical response, and the NRC has requested that both mode ls be placed in FRAPCON-2 for evaluation. $(18,19)$ The PELET mechanical package was developed by PNL, and the FRACAS-1 and FRACAS-2 mechanical packages were developed by INEL. 
TABLE 10. Computer Runs for Data/Code Comparison

\begin{tabular}{|c|c|c|c|}
\hline Case & Code & $\begin{array}{c}\text { Mechanical } \\
\text { Option } \\
\end{array}$ & Oensification 0ption \\
\hline 1 & GT3 & none & no densification (FROEN2 $=92 \%$ TD) \\
\hline 2 & GT3 & none & ex-reactor densification (FRDEN2 $=95.3 \% \mathrm{TD}$ ) \\
\hline 3 & GT3 & none & in-reactor densification (FRDEN2 $=96.5 \%$ TO) \\
\hline 4 & FRAPCON-1 & none & none $($ RSNTR $=0)$ \\
\hline 5 & FRAPCON-2 & $\operatorname{PELET}(a)$ & no densification (RSNTR $=0.01 \mathrm{~kg} / \mathrm{m}^{3}$ ) \\
\hline 6 & FRAPCON-2 & PELET & default densification (RSNTR $=0.0 \mathrm{~kg} / \mathrm{m}^{3}$ ) \\
\hline 7 & FRAPCON-2 & PELET & ex-reactor densification $\left(\right.$ RSNTR $\left.=362.0 \mathrm{~kg} / \mathrm{m}^{3}\right)$ \\
\hline 8 & FRAPCON-2 & FRACAS- $2^{(b)}$ & no densification (RSNTR $=0.01 \mathrm{~kg} / \mathrm{m}^{3}$ ) \\
\hline 9 & FRAPCON-2 & FRACAS-2 & default densification (RSNTR $=0.0 \mathrm{~kg} / \mathrm{m}^{3}$ ) \\
\hline 10 & FRAPCON-2 & FRACAS-2 & ex-reactor densification (RSNTR $=362.0 \mathrm{~kg} / \mathrm{m}^{3}$ ) \\
\hline
\end{tabular}

(a) PELET developed by PNL.

(b) FRACAS-2 developed by INEL.

Results from the 10 cases that were run are summarized in Table 11 . The data is from the upper thermocouple (high-power region) of rod 6 of IFA-431, and the code calculations correspond to that thermocouple location. In general, the following results were obtained:

- GT3 without densification (case 1) undercalculated temperatures while GT3 with densification (cases 2 and 3) overcalculated temperatures.

- FRAPCON-1 (case 4) overcaiculated temperatures.

- FRAPCON-2/PELET without densification (case 5) overcalculated temperatures and undercalculated temperatures with densification (cases 6 and 7 ).

- FRAPCON-2/FRACAS-2 overcalculated temperatures (cases 8, 9, and 10).

The comparisons are more easily seen in Table 12 where the difference between the code calculations and data is presented. Minimum differences occurred for the FRAPCON-2/FRACAS-2 run without densification (case 8 ) and the GT3 run using ex-reactor thermal resintering densification (case 2). 
TABLE 11. Results of Data/Code Comparison

Centerline Temperdture, $k$

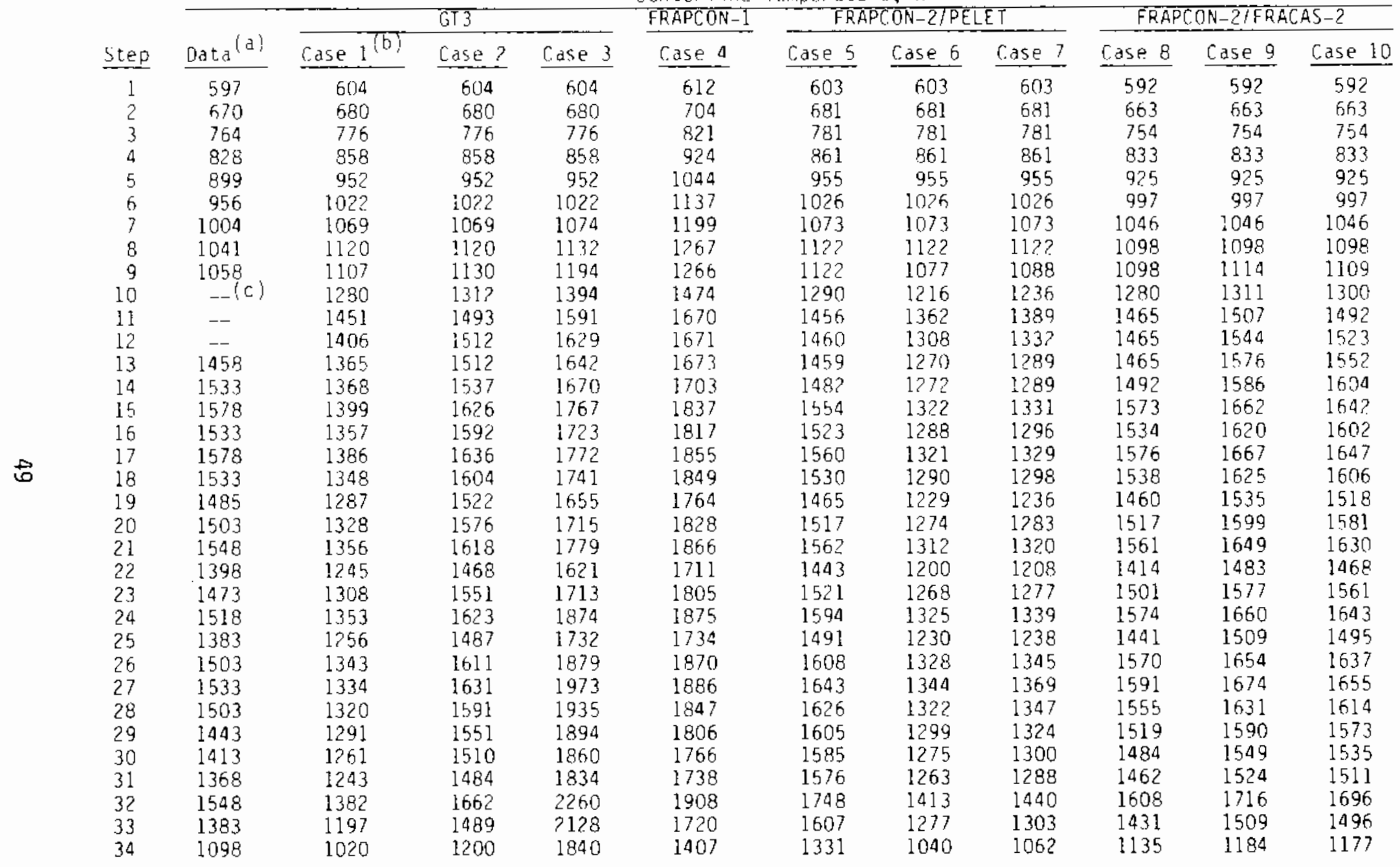

(a) Upper thermocouple.

(b) See Table 10 for definition of cases.

(c) Steps 10, 11 , and 12 were needed for code operation and were not compared to the data. 
TABLE 12. Comparison of Data and Code Results

Difference Between code Calcuiation and Data, (a) K

\begin{tabular}{|c|c|c|c|c|c|c|c|c|c|c|}
\hline \multirow[b]{2}{*}{ Step } & \multicolumn{3}{|c|}{ GT3 } & \multirow{2}{*}{$\frac{\text { FRAPCON-1 }}{\operatorname{case} 4}$} & \multicolumn{3}{|c|}{ FRAPCON-2/PELET } & \multicolumn{3}{|c|}{ FRAPCON-P/FRACAS-2 } \\
\hline & Case 1 & Case? & Case 3 & & Case 5 & Case 6 & $\operatorname{case} 7$ & సase 8 & Case 9 & Case 10 \\
\hline 1 & 7 & 7 & 7 & 15 & 6 & 6 & 6 & -5 & -5 & -5 \\
\hline 2. & 10 & 10 & 10 & 34 & 11 & 11 & 11 & -7 & -7 & -7 \\
\hline 4 & 30 & 30 & 30 & 96 & 33 & 33 & 33 & 5 & 5 & 5 \\
\hline 5 & $\ddot{3} 3$ & 53 & 53 & 145 & 56 & 56 & 56 & 26 & 26 & 26 \\
\hline 6 & 66 & 66 & 66 & 181 & 70 & 70 & 70 & 41 & 41 & 41 \\
\hline 9 & 49 & 72 & $\$ 36$ & 208 & 64 & 19 & 30 & 40 & 56 & 51 \\
\hline 10 & $-(b)$ & -- & -- & -- & -- & -- & -- & -- & -- & -- \\
\hline 11 & -- & -- & -- & -- & -- & -- & -- & $\ldots$ & -- & -- \\
\hline 12 & -- & - . & -- & -- & -- & - & $\ldots$ & -- & -- & -- \\
\hline 13 & -93 & 54 & 184 & 215 & 1 & -188 & -169 & 7 & 118 & 94 \\
\hline 14 & -170 & 4 & 137 & 170 & -51 & -261 & -244 & -41 & 53 & 71 \\
\hline 19 & -171 & 37 & 170 & 279 & 7 & -229 & $-22 ?$ & $?$ & 77 & 60 \\
\hline 20 & -175 & 73 & $2 ! 2$ & 325 & 14 & -229 & -220 & 14 & 96 & 78 \\
\hline 21 & -192 & 70 & 2.31 & 318 & 14 & -2.36 & -228 & 13 & 101 & 82 \\
\hline 22 & -153 & 70 & 223 & 313 & 45 & -198 & -190 & 16 & 85 & 70 \\
\hline 23 & -165 & 78 & 240 & $33 ?$ & 48 & -205 & -196 & 28 & 104 & 88 \\
\hline 24 & -165 & 105 & 356 & 357 & 76 & -193 & -179 & 56 & 142 & 125 \\
\hline 25 & -127 & 104 & 349 & 351 & 108 & -153 & -145 & 58 & 126 & 112 \\
\hline 26 & -160 & 108 & 376 & 367 & 105 & -175 & -158 & 67 & 151 & 134 \\
\hline 27 & -199 & 98 & 440 & 353 & 110 & .189 & -164 & 58 & 141 & 122 \\
\hline 28 & -183 & 88 & 432 & 344 & 123 & -181 & -156 & 52 & 128 & 111 \\
\hline 29 & -152 & 108 & 451 & 363 & 162 & -144 & -119 & 76 & 147 & 130 \\
\hline 30 & -152 & 97 & 447 & 353 & $17 ?$ & -138 & -113 & 71 & 136 & 122 \\
\hline
\end{tabular}

(a) A positive difference means the code calculation was greater than the data.

(b) Steps 10, 11 and 12 were needed for code operation and were not compared to the data. 
When densification is used in conjunction with FRAPCON-2/PELET, the calculated temperatures are less than when no densification is assumed due to the fuel model used in PELET(a) (see Table 12). Densification is applied by reducing the cold fuel diameter and thus increasing the amount of voidage, which increases the roughness and widths of the fuel cracks and the fuelcladding gap. However, an increase in the interaction between fuel fragments apparentiy accompanies the increased roughness, which increases the effective fuel thermal conductivity and reduces fuel temperatures.

When comparing data and code calculations, it is possible to define a band around the data within which a code calculation can be accepted. Two possible ways to define this acceptance band are:

- the uncertainty in the temperature measurement

- the uncertainty in the expected operating temperature given the uncertainty in fuel rod dimensions, material properties, and operating conditions.

The first definition results in a narrow band and requires that the code calculate the behavior of a specific rod that may or may not be typical of that design. The second definition results in a wider acceptance band that accounts for the expected behavior differences in nominally identical rods. Use of this second acceptance band allows the code to be compared to the expected general response of a rod design based on the actual specific response of that rod design.

Table 13 details the widths of the two acceptance bands. For the first band, the temperature measurement uncertainty is reported to be $\pm 3 \%$ at a confidence level of $30(99.7 \%$ confidence leve $)$, (20) which corresponds to approximately \pm 35 to $\pm 40 \mathrm{~K}$ during the steady-state portion of the irradiation.

The second acceptance band was determined by applying linear propagation of errors to the calculation of fuel temperature. $(21,22)$ By requiring that

(a) A complete discussion of the PELET mechanical package may be found in Reference 16. 
TABLE 13. Acceptance Bands for Data/Code Comparison

\begin{tabular}{|c|c|c|c|}
\hline Step & $\begin{array}{c}\text { Centerline } \\
\text { Temperature, } \mathrm{K}\end{array}$ & $\begin{array}{c}\text { Temperature } \\
\text { Measurement } \\
\text { Uncertainty, } \mathrm{K}(\mathrm{a}) \\
\end{array}$ & $\begin{array}{l}\text { Calculated } \\
\text { Operational } \\
\text { Uncertainty }(b) \\
\end{array}$ \\
\hline 1 & 597 & 10 & 33 \\
\hline 2 & 670 & 12 & 35 \\
\hline 3 & 764 & 15 & 50 \\
\hline 4 & 828 & 17 & 57 \\
\hline 5 & 899 & 19 & 64 \\
\hline 6 & 956 & 20 & 70 \\
\hline 7 & 1004 & 22 & 75 \\
\hline 8 & 1041 & 23 & 79 \\
\hline 9 & 1058 & 24 & 82 \\
\hline 10 & $--(c)$ & -- & -- \\
\hline 11 & -- & -- & -- \\
\hline 12 & -- & -- & -- \\
\hline 13 & 1458 & 36 & 137 \\
\hline 14 & 1533 & 38 & 151 \\
\hline 15 & 1578 & 39 & 154 \\
\hline 16 & 1533 & 38 & 147 \\
\hline 17 & 1578 & 39 & 154 \\
\hline 18 & 1533 & 38 & 147 \\
\hline 19 & 1485 & 36 & 139 \\
\hline 20 & 1503 & 37 & 144 \\
\hline 21 & 1548 & 38 & 149 \\
\hline 22 & 1398 & 34 & 131 \\
\hline 23 & 1473 & 36 & 140 \\
\hline 24 & 1518 & 37 & 143 \\
\hline 25 & 1383 & 33 & 127 \\
\hline 26 & 1503 & 37 & 141 \\
\hline 27 & 1533 & 38 & 146 \\
\hline 28 & 1503 & 37 & 144 \\
\hline 29 & 1443 & 35 & 135 \\
\hline 30 & 1413 & 34 & 132 \\
\hline 31 & 1368 & 33 & 124 \\
\hline 32 & 1548 & 38 & 148 \\
\hline 33 & 1383 & 33 & 129 \\
\hline 34 & 1098 & 25 & 2 \\
\hline
\end{tabular}

(a) Temperatures were measured in ${ }^{\circ} \mathrm{C}$ and uncertainty is based on as-measured temperatures.

(b) Calculation was performed in ${ }^{\circ} \mathrm{C}$; power uncertainty $=5.6 \%$ (Reference 20); and 3 confidence level.

(c) Steps 10, 11, and 12 were needed for code operation and were not compared to the data. 
the calculated centerline temperature match the data, the resulting uncertainty calculation can be interpreted as the expected range of temperature response given the dimensional and operating uncertainties. A code calculation that falls within this band $(\sim+140 K)$ is assumed to be reasonable.

By comparing Tables 12 and 13, it is possible to make the following statements about the thermal performance of the codes relative to the data.

- GT3 - If run without allowing densification, the calculated temperatures lie within the acceptance band during the rise to power. However, calculated temperatures are below the band throughout the steady-state irradiation. If run with a final density of $95.3 \%$ TD (thermal resintering result), the calculations lie within the acceptance band until the last step. Inputting a final density of $96.5 \%$ TD (from PIE) results in a strong overcalculation of temperature.

- FRAPCON-1 - Temperatures are greatly overcalculated using the default densification.

- FRAPCON-2/PELET - If run without densification, the calculated temperatures lie within the acceptance band until late in the power history, at which point temperatures are overcalculated. If run with either densification option, calculated temperatures are within the acceptance band during the rise to power. During steady-state irradiation, temperatures are undercalculated until late in the power history. (a)

- FRAPCON-2/FRACAS-2 - Except for scattered points late in the power history, calculated temperatures (with and without densification) lie within the acceptance band.

(a) Following the completion of this work and prior to publication, the anomalous result of densification that had caused a decrease in the calculated temperatures was traced to an error in the publicly available version of FRAPCON-2 (Version 1, Mod 2). With the error corrected, FRAPCON-2/PELET temperatures (with RSNTR $=362 \mathrm{~kg} / \mathrm{m} 3$ ) increased to values greater than the data but within the acceptance band until power history step 25 . The effect of porosity changes within the PELET/RADIAL model is under review. 



\section{REFERENCES}

1. U.S. AEC Reguiatory Staff. November 1972. Technical Report on Densification of Light Water Reactor Fuels. Washington, D.C.

2. Ditmore, D. C., and R. B. Elkins. December 1972. Densification Considerations in Boiling Water Reactor Fuel Design and Performance.

NEDM-10735, General Electric Co., San Jose, California.

3. U.S. AEC Regulatory Staff. September 1973. Technical Report on Densification of Exxon Nuclear BWR Fuels. Washington, D.C.

4. Buescher, B. J., and J. W. Pegram. July 1977. Babcock \& Wilcox Model for Predicting In-Reactor Densification. BAW-10083A, Rev. 1, Babcock \& Wilcox, Lynchburg, Virginia.

5. Stehle, H., and H. Assman. 1974. "The Dependence of In-Reactor $\mathrm{UO}_{2}$ Densification on Temperature and Microstructure." J. of Nuclear Materials 52:303-308.

6. Storhok, V.W. December 1974. Final Report on a Study of In-Reactor Densification of $\mathrm{UO}_{2}$ Fuel in the MH-1A Reactor. Battelle-Columbus Laboratories, columbus, ontio.

7. "A Sumary of CE Work on In-Pile Densification of Uranium Dioxide." Paper presented at the Government/Industry Working Meeting on $\mathrm{UO}_{2}$ and $\mathrm{ThO}_{2}$ Fuel Performance Technology, January 29-30, 1976, ERDA, Germantown, Maryland.

8. Freshley, M. D., et al. November 1976. "Irradiation-Induced Densification of $\mathrm{UO}_{2}$ Pellet Fuel." J. of Nuclear Materials 62:138-166.

9. Lindman, N. 1977. "On the Rate of In-Reactor $\mathrm{UO}_{2}$ Densification." J. of Nuclear Materials 71:73-77.

10. Meyer, R. 0. July 1976. The Analys is of Fuel Densification. NUREG-0085, U.S. Nuclear Regulatory Commission, Washington, D.C.

11. Neally, C., et al. October 1979. Post-Irradiation Data Analysis for NRC/PNL Halden Assembly IFA-431. NÜREG/CR-0797, PNL-2975, Pac if ic Northwest Laboratory, Richland, Washington.

12. Hann, C. R., et al. November 1977. Test Design, Precharacterization, and Fuel Assembly Fabrication for Instrumented Fuel Assemblies IFA-431 and IFA-432. NUREG/CR-0332, BNWL-1988, Pac if ic Northwest Laboratory, Richiand, Washington. 
13. Lanning, D. D., B. O. Barnes, and R. E. Williford. January 1979. Manifestations of Nonlinearity in Fuel Center Thermocouple Steady-State and Transient Data: Implications for Data Analysis. NUREG/CR-0220, PNL-2692, Pacific Northwest Laboratory, Richland, Washington.

14. Lanning, D. D., et al. January 1978. GAPCON-THERMAL-3 Code Description. PNL-2434, Pacific Northwest Laboratory, Richiand, Washington.

15. Berna, G. A., et a1. June 1980. FRAPCON-1: A Computer Code for the Steady State Analys is of 0xide Fuel Rods. NUREG/CR-1463, EGG-2039, Idaho National Engineering Laboratory, Idaho Falls, Idaho.

16. Berna, G. A., et al. December 1980. FRAPCON-2: A Computer Code for the Calculation of Steady State Thermal-Mechanical Behavior of Oxide Fuel Rods. NUREG/CR-1845, U.S. Nuc Tear Regulatory Commission, Washington, D.C.

17. Reymann, G. A., ed. February 1978. MATPRO-Version 10: A Handbook of Materials Properties for Use in the Analys is of Light Water Reactor Fuel Rod Behavior. TREE-NUREG-1180, Idaho National Engineering Laboratory, Idaho Falls, Idaho.

18. Berna, G. A., D. D. Lanning, and W. N. Rausch. June 1981. FRAPCON-2 Developmental Assessment. NUREG/CR-1949, Pac ific Northwest Laboratory, Richland, Washington.

19. Laats, E. T., et al. July 1981. Independent Assessment of the SteadyState Fuel Rod Analys is Code FRAPCON-2. EGG-CAAP-5335, EG\&G Idaho, Inc., Idaho Falls, Idaho.

20. Hann, C. R, , et al. February 1977. A Method for Determining the Uncertainty of Gap Conductance Deduced from Measured Centerline Temperatures. BNWL-2091, Pac if ic Northwe st Laboratory, Richland, Washington.

21. Cunningham, M. E., et al. May 1978. Stored Energy Calculation: The State of the Art. NUREG/CR-0320, PNL-2581, Pacific Northwest Laboratory, Richland, washington.

22. Cunningham, M. E., et al. September 1980. Application of Linear Propagation of Errors to Fuel Rod Temperature and Stored Energy CaTcuTations. NUREG/CR-1753, PNL-3539, Pac if ic Northwest Laboratory, Richland, Washington. 



\section{DISTRIBUTION}

No. of

Copies

OFFSITE

A. A. Churm

DOE Patent Division

9300 S. Cass Avenue

Argonne, IL 60439

400 U.S. Nuclear Regulatory Cormis sion

Division of Technical

Information and Document Control

7920 Norfolk Avenue

Bethesda, MD 20014

2 DOE Technical Information Center

4 G. P. Marino, Chief

Fuel Behavior Research Branch

Division of Reactor Safety Research

U.S. Nuclear Regulatory

Commission

Washington, DC 20555

H. H. Scott

Division of Reactor Safety Research

U.S. Nuclear Regulatory Commission

Washington, DC 20555
No. of

Copies

R. Van Houton

Fuel Behavior Research Branch

Division of Reactor Safety Research

U.S. Nuclear Regulatory

Cormission

Washington, DC 20555

ONSITE

50 Pacific Northwest Laboratory

W. J. Bailey

J. 0. Barner

E. R. Bradley

M. E. Cunningham (25)

J. L. Daniel

S. K. Edler

M. D. Freshley

R. L. Goodman

R. J. Guenther

C. R. Hann

D. D. Lanning

R. K. Marsha11

C. L. Mohr

C. Nealley

F. E. Panisko

W. N. Rausch

R. E. Schre iber

R. E. Williford

C. L. Wilson

Publishing Coordination (2)

Technical Information Yo(5) 



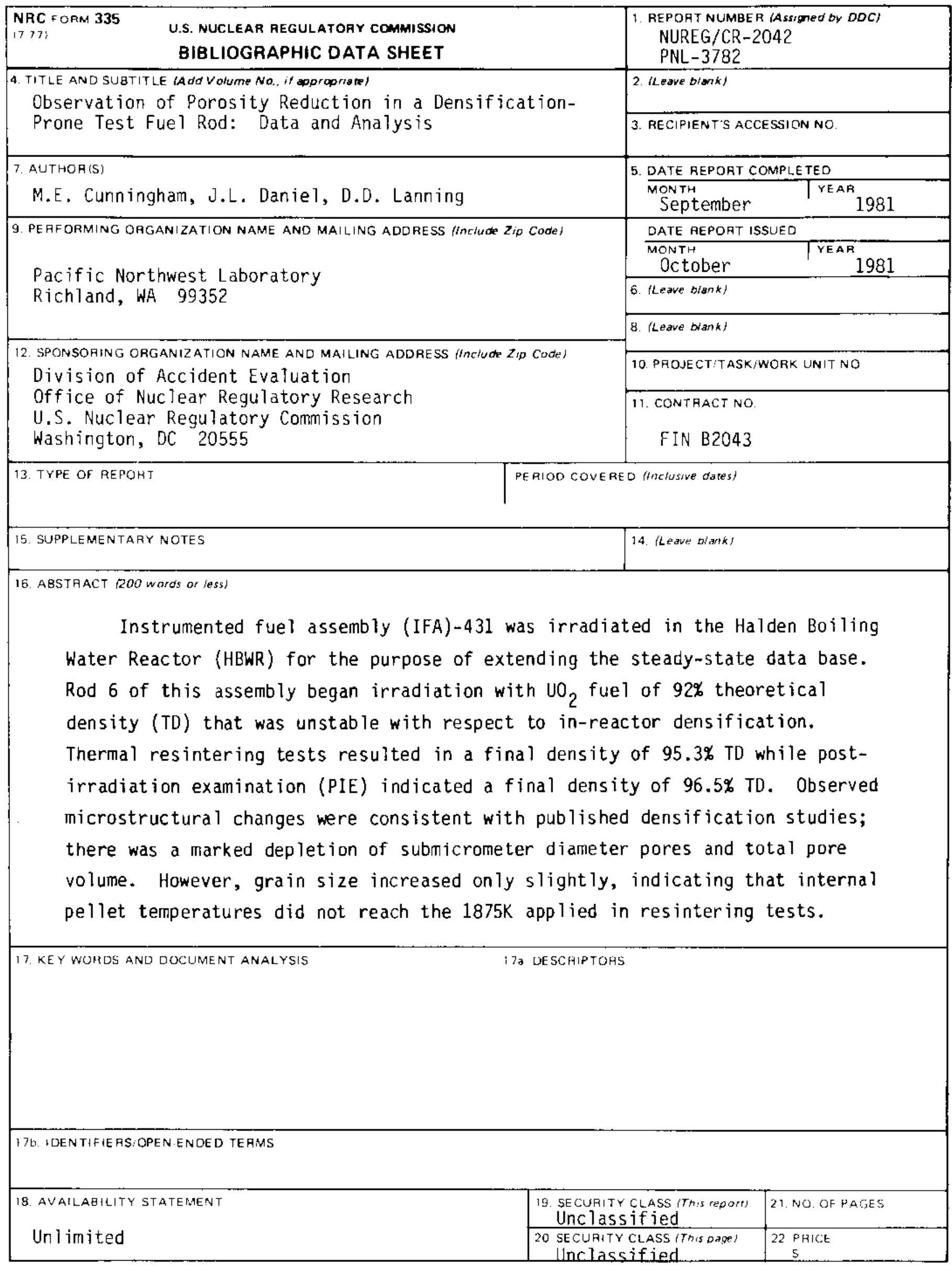

